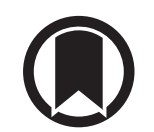

CrossMark

\title{
Obstructive sleep disordered breathing in 2- to 18-year-old children: diagnosis and management
}

\author{
Athanasios G. Kaditis ${ }^{1}$, Maria Luz Alonso Alvarez ${ }^{2}$, An Boudewyns ${ }^{3}$, \\ Emmanouel I. Alexopoulos ${ }^{4}$, Refika Ersu ${ }^{5}$, Koen Joosten ${ }^{6}$, Helena Larramona ${ }^{7}$, \\ Silvia Miano ${ }^{8}$, Indra Narang ${ }^{9}$, Ha Trang ${ }^{10}$, Marina Tsaoussoglou', \\ Nele Vandenbussche ${ }^{11}$, Maria Pia Villa ${ }^{12}$, Dick Van Waardenburg ${ }^{13}$, \\ Silke Weber ${ }^{14}$ and Stijn Verhulst ${ }^{15}$
}

\begin{abstract}
Affiliations: ${ }^{1}$ Pediatric Pulmonology Unit, First Dept of Paediatrics, University of Athens School of Medicine and Aghia Sophia Children's Hospital, Athens, Greece. ${ }^{2}$ Multidisciplinary Sleep Unit, Pulmonology, University Hospital of Burgos and CIBER of Respiratory Diseases (CIBERES), Burgos Foundation for Health Research, Burgos, Spain. ${ }^{3}$ Dept of Otorhinolaryngology Head and Neck Surgery, Antwerp University Hospital, University of Antwerp. Antwerp, Belgium. "Sleep Disorders Laboratory, University of Thessaly School of Medicine and Larissa University Hospital, Larissa, Greece. ${ }^{5}$ Division of Paediatric Pulmonology, Marmara University, Istanbul, Turkey. 'Erasmus MC, Sophia Children's Hospital, Paediatric Intensive Care, Rotterdam, The Netherlands. ${ }^{7}$ Paediatric Pulmonology Unit, Dept of Paediatrics, University Autonoma of Barcelona, Corporacio Sanitaria Parc Tauli, Hospital of Sabadell, Barcelona, Spain. ${ }^{8}$ Sleep and Epilepsy Centre, Neurocentre of Southern Switzerland, Civic Hospital of Lugano, Lugano, Switzerland. ${ }^{9}$ Division of Respiratory Medicine, Hospital for Sick Children, University of Toronto, Toronto, ON, Canada. ${ }^{10}$ Paediatric Sleep Centre, Robert Debré University Hospital, EA 7334 REMES Paris-Diderot University, Paris, France. ${ }^{11}$ Sleep Medicine Centre, Kempenhaeghe Foundation, Heeze, The Netherlands. ${ }^{12}$ Pediatric Sleep Disease Centre, Child Neurology, NESMOS Dept, School of Medicine and Psychology, Sapienza University of Rome, S. Andrea Hospital, Rome, Italy. ${ }^{13}$ Paediatric Intensive Care Unit, Dept of Paediatrics, Maastricht University Medical Centre, Maastricht, The Netherlands. ${ }^{14}$ Dept of Ophthalmology, Otolaryngology and Head and Neck Surgery, Botucatu Medical School, São Paulo State University-UNESP, Botucatu, São Paulo, Brazil. ${ }^{15}$ Dept of Paediatrics, Antwerp University Hospital, Edegem, Belgium.
\end{abstract}

Correspondence: Athanasios G. Kaditis, Paediatric Pulmonology Unit, First Dept of Paediatrics, University of Athens School of Medicine and Aghia Sophia Children's Hospital, Athens, Greece. E-mail: kaditialahotmail.com

ABSTRACT This document summarises the conclusions of a European Respiratory Society Task Force on the diagnosis and management of obstructive sleep disordered breathing (SDB) in childhood and refers to children aged 2-18 years. Prospective cohort studies describing the natural history of SDB or randomised, double-blind, placebo-controlled trials regarding its management are scarce. Selected evidence (362 articles) can be consolidated into seven management steps. SDB is suspected when symptoms or abnormalities related to upper airway obstruction are present (step 1). Central nervous or cardiovascular system morbidity, growth failure or enuresis and predictors of SDB persistence in the long-term are recognised (steps 2 and 3), and SDB severity is determined objectively preferably using polysomnography (step 4). Children with an apnoea-hypopnoea index (AHI) $>5$ episodes $\mathrm{h}^{-1}$, those with an AHI of 1-5 episodes $\cdot \mathrm{h}^{-1}$ and the presence of morbidity or factors predicting SDB persistence, and children with complex conditions (e.g. Down syndrome and Prader-Willi syndrome) all appear to benefit from treatment (step 5). Treatment interventions are usually implemented in a stepwise fashion addressing all abnormalities that predispose to SDB (step 6) with re-evaluation after each intervention to detect residual disease and to determine the need for additional treatment (step 7).

@ERSpublications

Management of obstructive sleep disordered breathing in childhood should follow a stepwise approach http://ow.ly/SdKwD

This article has supplementary material available from erj.ersjournals.com

Received: March 092015 | Accepted after revision: Aug 11 2015 | First published online: Nov 52015

Copyright @ERS 2016 


\section{Introduction}

Obstructive sleep disordered breathing (SDB) is not a distinct disease, but rather a syndrome of upper airway dysfunction during sleep characterised by snoring and/or increased respiratory effort secondary to increased upper airway resistance and pharyngeal collapsibility $[1,2]$. Obstructive SDB includes a spectrum of clinical entities with variable severity of intermittent upper airway obstruction (table 1) [3,4]. The term "obstructive SDB" is used when symptoms of intermittent upper airway obstruction during sleep are present but the severity of airway obstruction has not been defined by objective measures such as polysomnography.

In a meta-analysis of published studies, the prevalence of habitual snoring was $7.45 \%$ (95\% CI 5.75-9.61) [5]. The prevalence of obstructive sleep apnoea syndrome (OSAS) ranged from 0.1 to $13 \%$, but most studies demonstrated a frequency between 1 and 4\% [5]. Apnoea-hypopnoea index (AHI) is the most commonly reported polysomnographic parameter describing SDB severity in the literature.

\section{Unique characteristics of this ERS statement}

The unique characteristics of the current document compared with previously published guidelines [3, 6-12] (see the online supplementary material) are as follows. 1) It refers to the entire severity spectrum of obstructive SDB from primary snoring to OSAS in children aged 2-18 years old. 2) It discusses conditions other than adenotonsillar hypertrophy and obesity which can predispose to obstructive SDB, including craniofacial abnormalities and neuromuscular disorders. 3) It takes into account the available diagnostic facilities and accepted treatment policies in different European countries, and describes alternative diagnostic modalities that can be used in settings where polysomnography is not available. 4) It describes a step-by-step diagnostic and treatment approach.

\section{Methods}

The European Respiratory Society (ERS) Scientific Committee approved the development of a document on the diagnosis and management of obstructive sleep disordered breathing in childhood by a task force (TF-2012-09) in April 2012. Experts from several European countries and from countries outside Europe who were active within the ERS participated in the task force. All members signed forms disclosing conflicts of interest annually. The document contains a series of questions, formed by consensus of all task force members during two face-to-face meetings, with answers summarising the relevant literature. All answers have been incorporated into a stepwise management algorithm for children aged 2-18 years (fig. 1).

A systematic search of the literature was completed by the two chairs of the task force to answer the formulated questions. The MEDLINE, Scopus, Ovid, PsycINFO, EBSCO and CINAHL databases were searched for the period between January 1970 and December 2012. An additional search was performed covering January 2013 until December 2014 in order to identify recently published articles prior to preparation of the final document. Key words were: "adenoidectomy"; "adenoidal hypertrophy"; "adenotonsillar hypertrophy"; "polysomnography"; "sleep apnoea"; "sleep-disordered breathing"; "sleep-related breathing disorders"; "snoring"; "tonsillar hypertrophy"; "tonsillectomy"; "continuous positive airway pressure"; and "non-invasive positive pressure ventilation". The search was limited to articles in the English language and to humans aged 0-18 years. Articles on apnoea of prematurity were excluded. The methodological quality of the articles was graded as class I-IV according to the American Academy of Neurology Clinical Practice Guideline Process Manual [13]. The task force methodology for the preparation of this document is detailed in the online supplementary material.

\section{Results of the literature search}

The initial search provided 15149 titles. After excluding articles on apnoea of prematurity, OSAS in adults or non-humans, and articles not related to SDB as well as abstracts, letters and case reports, 3333 titles remained. Titles relevant to the topics of this document were selected: 58 on definition of obstructive SDB; 375 on risk factors; 277 on pathophysiology; 207 on symptoms; 356 on diagnosis; 510 on morbidity; 70 on natural history; and 464 on treatment. The additional literature search provided 140 references. Finally, 362 references were used to prepare the current document.

\section{Stepwise approach to the diagnosis and management of SDB}

Selected literature organised as a stepwise approach to the diagnosis and management of obstructive SDB is presented in figure 1. A brief summary of the available evidence follows each question and extensive description of the evidence along with additional references is presented in the online supplementary material.

Support statement: Preparation of this manuscript was supported financially by the European Respiratory Society (ERS Task Force 2012-09). Funding information for this article has been deposited with FundRef.

Conflict of interest: None declared. 
TABLE 1 Definitions of obstructive sleep disordered breathing and its clinical entities

Definition

\begin{tabular}{|c|c|}
\hline $\begin{array}{l}\text { Obstructive sleep disordered } \\
\text { breathing (SDB) }\end{array}$ & $\begin{array}{l}\text { A syndrome of upper airway dysfunction during sleep } \\
\text { characterised by snoring and/or increased respiratory } \\
\text { effort that result from increased upper airway resistance } \\
\text { and pharyngeal collapsibility }\end{array}$ \\
\hline \multicolumn{2}{|l|}{ Obstructive SDB clinical entities } \\
\hline Primary snoring & $\begin{array}{l}\text { Habitual snoring ( }>3 \text { nights per week) without apnoeas, } \\
\text { hypopnoeas, frequent arousals from sleep or gas } \\
\text { exchange abnormalities }\end{array}$ \\
\hline Upper airway resistance syndrome & $\begin{array}{l}\text { Snoring, increased work of breathing, frequent arousals, } \\
\text { but no recognisable obstructive events or gas exchange } \\
\text { abnormalities }\end{array}$ \\
\hline Obstructive hypoventilation & $\begin{array}{l}\text { Snoring and abnormally elevated end-expiratory carbon } \\
\text { dioxide partial pressure in the absence of recognisable } \\
\text { obstructive events }\end{array}$ \\
\hline Obstructive sleep apnoea syndrome & $\begin{array}{l}\text { Recurrent events of partial or complete upper airway } \\
\text { obstruction (hypopnoeas, obstructive or mixed apnoeas) } \\
\text { with disruption of normal oxygenation, ventilation } \\
\text { and sleep pattern }\end{array}$ \\
\hline
\end{tabular}

\section{Step 1: recognition of the child at risk for obstructive SDB \\ 1.1 Which symptoms reported by parents are directly related to intermittent upper airway obstruction?}

Summary

Frequent loud snoring, witnessed apnoeas, restless sleep and mouth breathing are associated with the presence of obstructive SDB.

\section{Literature review}

The relationship between snoring or other symptoms and OSAS has been described in at least two population-based, cross-sectional studies (class IV) [14, 15]. The most common definitions of habitual snoring are: "snoring present often/frequently" or ">3-4 nights per week" [5].

\subsection{Which findings on physical examination are associated with obstructive SDB?}

Summary

a) Clinical assessment of tonsillar size (Brodsky score) is a weak predictor of presence or severity of obstructive SDB. Neither Friedman palate position nor the Mallampati score predict SDB severity.

b) Allergic rhinitis may be associated with SDB and nasal septum deviation with habitual snoring. Nasal turbinate hypertrophy increases the risk of mild OSAS.

c) Obesity is an independent risk factor for obstructive SDB.

d) Retrusive chin, steep mandibular plane, vertical direction of craniofacial growth and a tendency towards class II malocclusion in non-syndromic children may contribute to obstructive SDB.

e) Midface deficiency (Apert syndrome, Crouzon syndrome, Pfeiffer syndrome, and unrepaired or repaired cleft palate) and marked mandibular hypoplasia (Pierre Robin sequence, Treacher Collins syndrome, Nager syndrome, Stickler syndrome and juvenile idiopathic arthritis) are associated with increased risk of obstructive SDB.

f) Neuromuscular disorders (cerebral palsy, Duchenne muscular dystrophy and myotonic muscular dystrophy) and uncontrolled epilepsy are related to a high risk for OSAS and nocturnal hypoventilation.

g) Complex abnormalities (achondroplasia, Chiari malformation, Down syndrome, Ehlers-Danlos syndrome, mucopolysaccharidoses and Prader-Willi syndrome) have been related to OSAS and alveolar hypoventilation. 


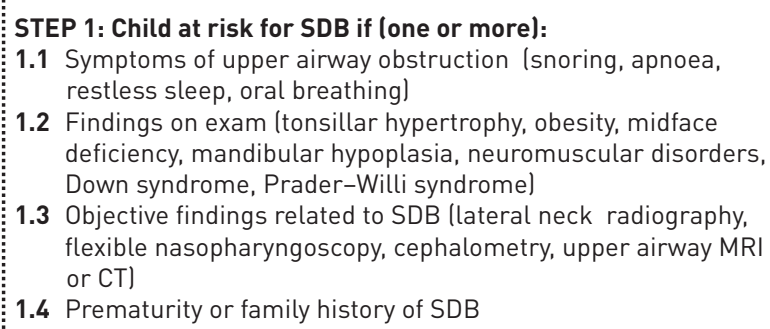

1.1 Symptoms of upper airway obstruction (snoring, apnoea, restless sleep, oral breathing)

1.2 Findings on exam Itonsillar hypertrophy, obesity, midface deficiency, mandibular hypoplasia, neuromuscular disorders, Down syndrome, Prader-Willi syndromel

1.3 Objective findings related to SDB (lateral neck radiography, flexible nasopharyngoscopy, cephalometry, upper airway MRI or CT)

1.4 Prematurity or family history of SDB

STEP 2: Recognition of morbidity and conditions coexisting with SDB:

\subsection{Morbidity}

Cardiovascular system

a) Elevated blood pressure

b) Pulmonary hypertension and cor pulmonale

Central nervous system

a) Excessive daytime sleepiness

b) Inattention/hyperactivity

c) Cognitive deficits/academic difficulties

d) Behavioural problems

Enuresis and somatic growth delay or growth failure

Decreased quality of life

2.2 Conditions coexisting with SDB (probably common pathogenesis)

a) History of recurrent otitis media or tympanostomy tube placement

b) Recurrent wheezing or asthma

c) Metabolic syndrome

STEP 4: Objective diagnosis and assessment of SDB severity

4.1 PSG or polygraphy if child at risk for SDB (see steps 1 and 2)

4.2 OSAS-definition 1: SBD symptoms in combination with obstructive $\mathrm{AHI} \geqslant 2$ episodes $\cdot \mathrm{h}^{-1}$ or obstructive apnoea index $\geqslant 1$ episode. $\mathrm{h}^{-1}$; OSAS-definition 2 : SDB symptoms and $\mathrm{AHI}$ $\geqslant 1$ episode $\cdot \mathrm{h}^{-1}$ (including central events)

4.3 If $\mathrm{AHI}>5$ episodes $\cdot \mathrm{h}^{-1}$ SDB unlikely to resolve spontaneously and child at risk for morbidity

4.4 If PSG or polygraphy not available: ambulatory PSG or polygraphy, nocturnal oximetry, Paediatric Sleep Questionnaire or Sleep Clinical Record

\section{d) Oral-motor dysfunction}

STEP 3: Recognition of factors predicting long-term persistence of SBD 3.1

a) Obesity and increasing BMI percentile

b) Male sex

c) Obstructive $\mathrm{AHI}>5$ episodes $\cdot \mathrm{h}^{-1}$

d) African-American ethnicity

e) Untreated tonsillar hypertrophy, narrow mandible

\section{STEP 5: Indications for treatment of SDB:}

5.1

a) $\mathrm{AHI}>5$ episodes $\cdot \mathrm{h}^{-1}$ irrespective of the presence of morbidity

b) Treatment may be beneficial if AHI 1-5 episodes $\cdot h^{-1}$ especially in the presence of: morbidity from the cardiovascular system (see 2.1); morbidity from the central nervous system (see 2.1); enuresis; somatic growth delay or growth failure; decreased quality of life; risk factors for SDB persistence (see 3)

c) If at risk for SDB and PSG or polygraphy not available, treatment is considered when positive oximetry or SDB questionnaires (see 4.4) or morbidity present

$\mathbf{5 . 2}$ Unclear whether should treat primary snoring (evaluation annually)

5.3 OSAS treatment is a priority in the presence of: major craniofacial abnormalities; neuromuscular disorders; achondroplasia; Chiari malformation; Down syndrome; mucopolysaccharidoses; Prader-Willi syndrome

STEP 6: Stepwise treatment approach to SDB\#:

6.1 A stepwise treatment approach (from 6.2 to 6.9) is usually implemented until complete resolution of SDB

6.2 Weight loss if the child is overweight or obese

6.3 Nasal corticosteroids and/or montelukast p.o.

6.4 Adenotonsillectomy

6.5 Unclear whether adenoidectomy or tonsillectomy alone are adequate

6.6 Rapid maxillary expansion or orthodontic appliances

6.7 CPAP or NPPV (for nocturnal hypoventilation)

6.8 Craniofacial surgery

6.9 Tracheostomy

\section{STEP 7: Recognition and management of persistent SDB:}

7.1

a) Outcomes monitored after intervention (6 weeks-12 months): symptoms, PSG, quality of life, cardiovascular or central nervous system morbidity, enuresis, growth rate

b) If PSG not available: polygraphy, oximetry/capnography

c) PSG $\geqslant 6$ weeks after adenotonsillectomy (persistent SDB symptoms or at risk of persistent OSAS preoperatively); after 12 weeks of montelukast/nasal steroid

d) PSG after 12 months of rapid maxillary expansion (earlier if symptoms persist) and after 6 months with an oral appliance

e) PSG for titration of CPAP, NPPV and then annually; PSG as predictor of successful decannulation with tracheostomy

f) Airway re-evaluation by nasopharyngoscopy, drug-induced sleep endoscopy, MRI

FIGURE 1 A stepwise approach to the diagnosis and management of obstructive sleep disordered breathing (SDB) in 2-18 year-old children. MRI: magnetic resonance imaging; CT: computed tomography; BMI: body mass index; AHI: apnoea-hypopnoea index; PSG: polysomnography; OSAS: obstructive sleep apnoea syndrome; CPAP: continuous positive airway pressure; NPPV: noninvasive positive pressure ventilation. \#: for details on indications, efficacy, adverse effects or complications of different treatment interventions see the main text. 
Literature review

a) In children with snoring, the adenoid and tonsils are large early in life and remain enlarged during late childhood and adolescence (class IV) [16]. The association between tonsillar size evaluated subjectively and OSAS severity as determined by polysomnography is weak at best. High-quality studies suggest no association (meta-analysis) (class I) [17, 18]. Grading systems for pharyngeal anatomy, such as the Friedman palate position or the Mallampati score, are not related to AHI in children with symptoms of SDB (class I and IV) [19].

b) Evidence for the association between allergic rhinitis and OSAS comes from studies of low methodological quality [20]. Nasal septum deviation increases the risk for habitual snoring (class IV) and nasal turbinate hypertrophy is associated with mild OSAS (class I) [21, 22].

c) Class II-IV studies suggest that obesity is a risk factor for OSAS [23, 24], but the evidence is conflicting [25-27].

d) One meta-analysis identified craniofacial characteristics consistent with OSAS [28], whereas a second meta-analysis suggested that the differences between children with SDB and controls are of marginal clinical significance [29].

e) All relevant publications are of class III or IV [30-32]. Not all studies concluded that repair of cleft palate increases the risk of OSAS [32-34].

f) Most studies are class III or IV and do not clearly describe risk factors for OSAS in children with neuromuscular disorders [35-37]. Absence of diurnal or nocturnal symptoms does not exclude OSAS [38]. An inspiratory vital capacity of $<60 \%$ may predict OSAS and $<40 \%$ may predict OSAS with nocturnal hypoventilation [39]. In children with Duchenne muscular dystrophy, age $<10$ years is associated with obstructive SDB and adolescence is associated with the presence of sleep hypoventilation (class IV) [38]. Among children with epilepsy and symptoms of SDB, those with uncontrolled epilepsy more frequently have OSAS than primary snoring (class IV) [40]. Children with OSAS have increased frequency of interictal epileptiform discharges (class IV) [41].

g) Class III or IV studies have demonstrated a high prevalence of OSAS and central apnoeas in children with achondroplasia (midface hypoplasia and brainstem compression) [42-44]. Chiari malformation is accompanied by obstructive and central apnoeas and hypoventilation with risk factors being the degree of brainstem crowding at the foramen magnum and the length of herniation (class III-IV) [45-48]. Children with Down syndrome are predisposed to OSAS and hypoventilation due to midfacial and mandibular hypoplasia, shortened palate, relative macroglossia, narrow lumen of the nasopharynx and pharyngeal hypotonia, although parents may not report SDB symptoms (Class III-IV) [49-51]. Age $<8$ years, male sex and tonsillar hypertrophy are risk factors for OSAS in children with Down syndrome [51,52]. Ehlers-Danlos syndrome has been associated with SDB (class IV) [53]. Mucopolysaccharidoses represent a group of rare lysosomal storage diseases and the reported high prevalence of OSAS has been attributed to the narrowed upper airway lumen (class IV) [54-56]. The majority of children with Prader-Willi syndrome have OSAS, mostly of mild severity (quantitative review) [57]. The severity of OSAS increases with younger age and higher body mass index (BMI) z-score [57]. Children younger than 2 years more frequently have central apnoeas than older children [58].

\subsection{Which techniques can be used for the objective evaluation of abnormalities predisposing to obstructive SDB? \\ Summary}

a) Increased adenotonsillar tissue size as demonstrated by lateral neck radiography (adenoid/ nasopharyngeal ratio or tonsillar/pharyngeal ratio $>0.5$ ) has good sensitivity but poor specificity for OSAS, which can be improved with the assimilation of clinical factors (mouth breathing and enuresis).

b) Flexible nasopharyngoscopy under local anaesthesia sometimes replaces lateral radiography to avoid radiation exposure.

c) Cephalometry, magnetic resonance imaging (MRI) or computed tomography (CT) of the upper airway, functional respiratory imaging, and acoustic pharyngometry are useful for the evaluation of pharyngeal airway size in selected cases.

\section{Literature review}

a) Low quality studies (class III-IV) suggest that increased adenotonsillar tissue size as detected by lateral neck radiography overdiagnoses OSAS in children [59-61].

b) Flexible nasopharyngoscopy has been used in otherwise healthy children with SDB and in young children with Pierre Robin sequence (class IV) [26, 62]. 
c) Cephalometry is a standardised lateral radiographic view of the head incorporating skeletal and soft-tissue structures (systematic review and meta-analysis) [29]. MRI of the upper airway has been applied in studies of children with OSAS and adenotonsillar hypertrophy and/or obesity (class III-IV) [16, 63-65]. CT scanning has been applied in complex patients (e.g. those with mandibular hypoplasia and mucopolysaccharidoses), but its disadvantage is radiation exposure (class IV) [66,67]. There is limited evidence for the clinical value of functional respiratory imaging (a CT scan with three-dimensional reconstruction of the pharynx and computational fluid dynamics modelling of inspiratory flow) and acoustic pharyngometry (class IV) [68-70].

\subsection{Which conditions from past medical and family history are significant predictors of} obstructive SDB?

Summary

a) History of prematurity.

b) Parental history of OSAS or adenotonsillectomy in childhood as well as sibling history of OSAS or adenotonsillar hypertrophy.

\section{Literature review}

a) One class I and several class III and IV studies support the association between a history of prematurity and obstructive SDB [71-73].

b) Low-quality evidence (class III-IV) indicates an increased risk of OSAS and adenotonsillar hypertrophy in children with a family history of OSAS or enlarged pharyngeal lymphoid tissue [74-77].

\section{Step 2: recognition of morbidity and conditions frequently coexisting with SDB}

2.1. Which abnormalities have increased prevalence in children and adolescents with obstructive SDB and reflect associated morbidity?

Summary

Morbidity from the cardiovascular system

a) Elevated blood pressure ( $\sim 3.5 \mathrm{mmHg}$ elevation in wake and sleep systolic and diastolic blood pressure), rarely exceeding the 95th percentile value, has been demonstrated in children with AHI $>5$ episodes $\cdot \mathrm{h}^{-1}$. When blood pressure exceeds the 95th percentile value in the context of snoring, the possibility of OSAS needs to be ruled out.

b) Children with severe OSAS are at risk of pulmonary hypertension and cor pulmonale especially in the presence of complex disorders (e.g. Down syndrome, Duchenne muscular dystrophy and mucopolysaccharidoses)

Morbidity from the central nervous system

a) Children with obstructive SDB and especially those who are obese tend to have excessive daytime sleepiness.

b) Obstructive SDB irrespective of its severity is associated with increased frequency of inattention/ hyperactivity symptoms.

c) Children with obstructive SDB may have increased prevalence of cognitive deficits and academic difficulties (general intelligence, verbal intelligence, executive function, learning, memory, visuospatial skills, language, phonological skills, concept formation, analytical thinking and mathematical abilities).

d) Children with SDB have increased frequency of behavioural disorders (conduct problems, emotional lability, anxiety and depressive symptoms).

Enuresis and somatic growth delay or growth failure

a) Prevalence of nocturnal enuresis is positively correlated with severity of obstructive SDB.

b) Children with obstructive SDB are at risk of reduced somatic growth rate or even growth failure (weight or height below the fifth percentiles for age and sex).

\section{Decreased quality of life}

SDB has been associated with caregiver concerns regarding sleep disturbance, general health status, daytime functioning, behavioural problems and academic performance. 
Literature review

Morbidity from the cardiovascular system

a) A meta-analysis did not demonstrate an association between OSAS and blood pressure [78]. Four subsequent cross-sectional studies (class IV) identified a significant association [79-82], but one casecontrol study did not confirm this finding [83]. In a published consensus statement on childhood hypertension, polysomnography for the exclusion of OSAS in children presenting with hypertension and snoring is recommended [84]. Average nocturnal heart rate increases with increasing AHI (3 beats per minute higher for an AHI of 10 episodes $\cdot h^{-1}$ as compared with 2 episodes $\cdot h^{-1}$ ) (class I) [85].

b) Low-quality evidence supports this association (class IV) [55, 86-89]. Effects of OSAS on left ventricle structure and function are subtle and without clinical importance in otherwise healthy children.

Morbidity from the central nervous system

a) The association between excessive daytime sleepiness and OSAS is supported mainly by studies of low methodological quality (class IV) [90-93]. Few studies have employed multiple sleep latency tests (class I and III) [94-96].

b) Three meta-analyses have addressed the association between attention deficit/hyperactivity symptoms and SDB, and the most recent of them has demonstrated significant results [97-99]. Published data from the Tucson Children's Assessment of Sleep Apnoea Study (TuCASA study) (a prospective, population-based cohort) indicate a significant relationship between SDB and hyperactivity/inattention (class I) [100].

c) Studies of low methodological quality (class III or IV) reveal that children with SDB have an increased prevalence of cognitive impairment and academic difficulties, which does not correlate with polysomnography indices $[101,102]$. In a large population-based cohort study, children with mild SDB showed no significant impairment in intelligence, verbal and nonverbal reasoning ability, attention, executive functioning, memory, processing speed and visual-motor skill compared with children without SDB (class I) [103].

d) Results of the TuCASA study reveal a significant association of SDB with behavioural problems (aggression, lower social competency, poorer communication and/or diminished adaptive skills) (class I) [100]. This association has also been found in studies of low methodological quality (class III or IV) [104, 105].

Enuresis and somatic growth delay or growth failure

a) Three class IV studies support an association between frequency of nocturnal enuresis and SDB severity [106-108]. Resolution or decreased frequency of enuresis after treatment of SDB is indicative of an aetiological relationship between the two conditions as suggested by a systematic review [109].

b) In six out of 20 studies included in a systematic review and meta-analysis, growth failure was reported in a proportion of participants with SDB [110]. After adenotonsillectomy, a significant increase in weight and height $\mathrm{z}$-scores was noted [110].

Decreased quality of life

In a meta-analysis of 10 studies, children with OSAS had poorer scores in the Child Health Questionnaire than healthy children and similar scores to those of patients with juvenile rheumatoid arthritis [111]. Starting early in life, children with OSAS have increased utilisation of healthcare services, mostly related to respiratory morbidity and thus increased societal costs (class III) [112]. Both generic and disease-specific health-related quality of life measures improve after adenotonsillectomy (class I) [113].

\subsection{Which conditions frequently coexist with obstructive SDB (possibly common pathogenetic mechanisms) and may potentially improve with treatment of SDB?}

Summary

a) Obstructive SDB is associated with recurrent otitis media and history of tympanostomy tube placement.

b) Recurrent wheezing or asthma frequently coexists with obstructive SDB and low quality evidence indicates that adenotonsillectomy may improve asthma outcomes.

c) Metabolic syndrome frequently coincides with SDB and weight loss may improve both conditions.

d) Oral-motor dysfunction (difficulties with chewing, swallowing and articulation) may coexist with adenotonsillar hypertrophy and obstructive SDB, and may improve following adenotonsillectomy.

Literature review

a) In a large population-based study, habitual snoring was a risk factor for recurrent otitis media and the need for tympanostomy tube placement (class IV) [114]. 
b) In a systematic review, increased prevalence of snoring or elevated AHI has been demonstrated in children with history of wheezing or physician-diagnosed asthma [115]. In a class III report, SDB was a predictor of asthma severity, and in two retrospective cohort studies, adenotonsillectomy was accompanied by improved asthma outcomes (class II and IV) [116-118].

c) A few cross-sectional studies (class IV) (population-based or hospital-referred subjects) showed an increased prevalence of the metabolic syndrome among children with OSAS or associations between polysomnography indices and components of the metabolic syndrome [119, 120].

d) Adenotonsillar hypertrophy can be accompanied by dysfunction in chewing, swallowing and speech, which may improve after adenotonsillectomy (class IV) [121-124].

\section{Step 3: recognition of factors predicting long-term persistence of obstructive SDB}

3.1. Is there evidence from short-term controlled studies or long-term prospective studies

regarding predictors of spontaneous resolution or long-term persistence of untreated

obstructive SDB?

Summary

Risk factors for persistence of untreated SDB are as follows.

a) Obesity and increasing BMI percentile

b) Male sex

c) Severity of OSAS (obstructive AHI $>5$ episodes $\cdot h^{-1}$ ) (step 4)

d) African-American ethnicity

e) Persistent tonsillar hypertrophy and a narrow mandible

Literature review

a-d) Risk factors for persistence of untreated OSAS were identified in three prospective, cohort studies (class I) [125-127].

e) Persistent, untreated tonsillar hypertrophy and a narrow mandible predict persistent SDB (class III) $[128,129]$.

\section{Step 4: objective diagnosis and assessment of obstructive SDB severity}

4.1. What are the indications for in-laboratory polysomnography and polygraphy lairflow monitoring, chest and abdominal wall movements, and pulse oximetryl in the context of obstructive SDB?

Summary

a) Polysomnography or polygraphy is indicated in children with symptoms of obstructive SDB and prior to adenotonsillectomy especially in the presence of: obesity; craniofacial deformities; neuromuscular disorders; complex abnormalities (e.g. Chiari malformation, Down syndrome and Prader-Willi syndrome); or when the need for treatment is unclear.

b) Polysomnography or polygraphy has been recommended post-adenotonsillectomy in patients with: persistent symptoms of OSAS despite surgery; moderate-to-severe OSAS preoperatively; and obesity, craniofacial deformities, neuromuscular disorders or complex abnormalities (e.g. Chiari malformation, Down syndrome and Prader-Willi syndrome).

c) Polysomnography or polygraphy is indicated prior to and after rapid maxillary expansion or application of orthodontic appliances, continuous positive airway pressure (CPAP) and noninvasive positive pressure ventilation (NPPV) for treating OSAS.

\section{Literature review}

a-c) The literature on indications for polysomnography has been summarised by a Task Force of the American Academy of Sleep Medicine (AASM) [11, 12]. In the American Academy of Pediatrics Clinical Practice Guideline on childhood OSAS, objective testing is recommended for the diagnosis of OSAS and overnight, attended, in-laboratory polysomnography is considered the gold standard test [7]. Nocturnal video recording, nocturnal oximetry, daytime nap polysomnography, or ambulatory polysomnography are proposed as alternative diagnostic modalities if nocturnal, in-laboratory polysomnography is not available. An American Academy of Otolaryngology - Head and Neck Surgery Clinical Practice Guideline limited the indications for polysomnography prior to tonsillectomy to children at risk for OSAS due to obesity, Down syndrome, craniofacial abnormalities, neuromuscular disorders, sickle cell disease or mucopolysaccharidoses [130]. In addition, polysomnography is recommended in children without comorbidities but for whom the 
need for treatment is uncertain or there is discordance between the reported severity of SDB and the size of the tonsils. The ERS Task Force members agree that polysomnography is the gold standard test for the diagnosis of OSAS and assessment of its severity. Polysomnography may not always be fiscally or practically feasible, in which case one or more of the alternative objective diagnostic methods described in section 4.4 (i.e. nocturnal oximetry or validated questionnaires) should be used instead. Previously untreated, otherwise healthy, non-obese children at risk for obstructive SDB due to adenotonsillar hypertrophy may be of low priority for polysomnography.

\subsection{What are the cut-off values of cardiorespiratory parameters in polysomnography or polygraphy for the diagnosis of OSAS? \\ Summary}

a) Rules for the scoring of sleep and respiratory events in polysomnography or polygraphy recordings are provided in the AASM manual [9]. The AHI (the number of mixed, obstructive and central apnoeas and hypopnoeas per hour of total sleep time) is the most commonly used polysomnography parameter for the description of SDB severity.

b) Central apnoeas are included in the AHI as stated in the AASM scoring rules. It is helpful to report the central apnoea index and obstructive AHI (i.e. AHI without incorporating central apnoeas). An elevated central apnoea index $\left(>1\right.$ episode $\left.\cdot \mathrm{h}^{-1}\right)$ in children with obstructive SDB may decrease post-adenotonsillectomy.

c) The upper centiles of the frequency of respiratory events (apnoeas, hypopnoeas and desaturation events) in asymptomatic children and the lower centiles in children with SDB overlap. Therefore, polysomnography parameters are interpreted taking into consideration the presence of symptoms and SDB-related morbidity, and the expected response to treatment interventions.

d) In children without SDB symptoms or morbidity, or abnormalities predisposing to SDB, the 90th percentile for the AHI (AASM 2007 scoring rules) is 3.2 episodes $\cdot \mathrm{h}^{-1}$ for the second year of life, up to 2.5 episodes $\cdot h^{-1}$ for the ages $>2$ and $\leqslant 6$ years, and up to 2.1 episodes $\cdot h^{-1}$ for the ages $>6$ and $<18$ years.

e) OSAS definition 1: if OSAS is defined as an obstructive AHI $\geqslant 2$ episodes $\cdot h^{-1}$ or an obstructive apnoea index (obstructive apnoeas per total sleep time) $\geqslant 1$ episode $h^{-1}$ in the presence of SDB symptoms, adenotonsillar hypertrophy with or without obesity and no other abnormalities, it is likely that the AHI will become normal after adenotonsillectomy. This likelihood is lower with mild OSAS (obstructive AHI of 2-5 episodes $\cdot h^{-1}$ ) than with moderate-to-severe OSAS (obstructive AHI $>5$ episodes $\cdot h^{-1}$ ).

f) OSAS definition 2 (used in most published studies): when OSAS is defined as SDB symptoms in combination with an AHI $\geqslant 1$ episode $\mathrm{h}^{-1}$, there is improvement in symptoms of inattention and hyperactivity following adenotonsillectomy. Children with moderate-to-severe OSAS (AHI $>5$ episodes $\cdot \mathrm{h}^{-1}$ ) have significant elevations in average wake systolic, and wake and sleep diastolic blood pressure compared with controls (AHI $\leqslant 1$ episode $\cdot h^{-1}$ ).

g) In children without craniofacial or neuromuscular disorders, AHI $>1$ episode $\cdot \mathrm{h}^{-1}$ on polygraphy predicts AHI $>1$ episode $\cdot \mathrm{h}^{-1}$ on polysomnography with moderate sensitivity (88\%) and specificity (71\%).

h) It is difficult to distinguish primary snoring from upper airway resistance syndrome without using an oesophageal catheter. Differentiation of the two entities is of unknown clinical importance. Primary snoring (AHI $<1$ episode $\cdot \mathrm{h}^{-1}$ and no associated gas exchange abnormalities or frequent arousals) might be accompanied by elevated blood pressure or increased risk of morbidity from the central nervous system. The effects of treatment interventions are unclear.

\section{Literature review}

a, b) According to the 2012 update of the AASM manual either paediatric or adult scoring rules may be used for adolescents between 13 and $<18$ years of age [10]. Application of the paediatric scoring rules results in a higher value for the AHI and, potentially, in more adolescents being diagnosed with OSAS $[131,132]$. Inclusion of central apnoeas in the AHI is recommended in the 2007 AASM manual and its 2012 update $[9,10]$. Central apnoeas in children are associated with fluctuations in heart rate and blood pressure, and movement-induced central apnoeas (after movement or sigh) are more common in children with OSAS (class IV) [133]. There is one class IV study demonstrating reduction in the central apnoea index in children with OSAS post-adenotonsillectomy [134].

c, d) In a class III multicentre study, median, 10th and 90th percentile values of polysomnography parameters for 1-18 year-old healthy, non-obese children without symptoms of SDB were reported. Values presented in statement 4.2, point $\mathrm{d}$ above have been adjusted to the AASM scoring rules [135]. Reference values have also been provided in older studies prior to publication of the AASM scoring rules [136-144]. 
e) The Childhood Adenotonsillectomy Trial (CHAT) indicated that children who fulfilled the criteria for OSAS definition 1 had a higher frequency of a normal polysomnography following adenotonsillectomy than untreated controls (class I) [126]. Normalisation of polysomnography parameters following adenotonsillectomy is more frequent in children with obstructive AHI $>4.7$ episodes $\cdot \mathrm{h}^{-1}$ (moderate-to-severe OSAS) than in children with lower AHI (mild OSAS) (class I) [126].

f) OSAS definition 2 is supported by a recent meta-analysis demonstrating that adenotonsillectomy for an AHI $\geqslant 1$ episode. $h^{-1}$ is accompanied by modest improvement in symptoms of inattention and hyperactivity [145]. Children with AHI $>5$ episodes $\cdot h^{-1}$ have increased risk of elevated blood pressure compared with healthy controls (class III) [81]. There are no high-quality studies supporting the validity of OSAS definitions 1 and 2 in children with abnormalities other than adenotonsillar hypertrophy or obesity (e.g. craniofacial abnormalities or neuromuscular disorders).

g) A cut-off AHI $>1$ episode $\cdot \mathrm{h}^{-1}$ for the diagnosis of OSAS by polygraphy is based on the meta-analysis of two studies [146].

h) Very limited evidence supports the relationship between primary snoring and elevated blood pressure (class IV) [147]. A review article has summarised evidence on cognitive and behavioural deficits in children with primary snoring [148]. No evidence for the beneficial effects of treatment interventions for primary snoring is available.

\subsection{What is the value of assessing obstructive SDB severity objectively?}

Summary

a) Severity of obstructive SDB is positively associated with risk of morbidity and more specifically elevated blood pressure and enuresis but not presence of sleepiness, behavioural and cognitive abnormalities.

b) Moderate-to-severe OSAS is less likely to resolve without treatment when compared with mild OSAS.

c) Frequency of respiratory complications in the immediate post-adenotonsillectomy period has been reported to increase with increasing severity of OSAS as measured by polysomnography parameters. However, the frequency of post-operative respiratory complications in school-aged children without comorbidities is low irrespective of the OSAS severity.

d) Likelihood of residual OSAS after adenotonsillectomy increases in parallel with preoperative disease severity.

\section{Literature review}

a) Children with $\mathrm{AHI}>5$ episodes $\cdot \mathrm{h}^{-1}$ have an increased risk of elevated blood pressure compared with healthy controls (class III) [81]. Primary nocturnal enuresis among children with snoring referred for polysomnography is a significant predictor of OSAS severity (class IV) [106]. However, neither the AHI nor sophisticated measures of sleep fragmentation, such as respiratory cycle-related electroencephalogram (EEG) changes, are associated with behavioural problems, cognitive deficits or sleepiness, and they do not explain the improvement in neurobehavioral outcomes following adenotonsillectomy (meta-analysis, class III and IV) [92, 145, 149, 150].

b) In the CHAT study, participants with moderate-to-severe disease (AHI $>4.7$ episodes $\cdot \mathrm{h}^{-1}$ ) assigned to watchful waiting were less likely to improve spontaneously compared with those with mild disease (class I) [126].

c) In class II-IV studies, severity of OSAS was a significant predictor of respiratory complications (reintubation, unplanned intensive care unit (ICU) admission or interventions to prevent airway compromise such as bag-mask ventilation, CPAP, nasopharyngeal or oropharyngeal airway placement) post-adenotonsillectomy [151-153]. AHI $>26$ episodes $\cdot h^{-1}$ and more than three drops in oxygen saturation of haemoglobin below $90 \%$ were significant predictors of post-operative respiratory complications (class IV) $[152,154]$. In the CHAT study, the frequency of respiratory complications in school-aged children without comorbidities were low (1.4\%) and was not predicted by OSAS severity (class I) [155].

d) In the CHAT study, moderate-to-severe OSAS at baseline was a significant risk factor for OSAS persistence post-adenotonsillectomy (class III) [126]. However, a multicentre retrospective study provided less convincing evidence for the importance of OSAS severity as a predictor of disease persistence post-operatively (class IV) [156].

\subsection{What are the alternative tools for the diagnosis of obstructive SDB if polysomnography or polygraphy are not available? \\ Summary}

None of the alternative methods can substitute for polysomnography but they may be used in low resource settings. 
a) Ambulatory polysomnography or most often polygraphy (an unattended sleep study at home) is feasible and has been used as alternative to in-laboratory polysomnography.

b) Nocturnal pulse oximetry (continuous recording with trend analysis and an averaging time of $3 \mathrm{~s}$ or less): an abnormal oximetry (three or more clusters of desaturation events $\geqslant 4 \%$ and at least three desaturations to $<90 \%$, known as the McGill criteria) is used for the diagnosis and treatment of the most severe OSAS cases but the rate of false negative or inconclusive results is high; children with Down syndrome have high prevalence of OSAS as reflected by abnormal oximetry; in 2-18 year-old healthy children without symptoms of SDB, the 90th percentile of the oxygen desaturation $(\geqslant 3 \%)$ index does not exceed 1.2 episodes $\cdot \mathrm{h}^{-1}$; and an oxygen desaturation $(\geqslant 4 \%)$ of haemoglobin index $>2$ episodes $\cdot \mathrm{h}^{-1}$ in children with adenotonsillar hypertrophy and snoring predicts an AHI of $>1$ episode $\cdot \mathrm{h}^{-1}$ with variable sensitivity and specificity.

c) The pulse transit time arousal index may be useful for the detection of respiratory events.

d) The Brouillette score and OSA-18 score (quality of life) have poor sensitivity and specificity for the prediction of polysomnography results.

e) The Paediatric Sleep Questionnaire is a useful tool for the prediction of obstructive AHI $>5$ episodes $\cdot \mathrm{h}^{-1}$, OSAS-related neurobehavioural morbidity and its improvement after adenotonsillectomy.

f) A score $\geqslant 6.5$ in the Sleep Clinical Record among children with snoring has high sensitivity and low specificity in diagnosing OSAS (AHI $>1$ episode $\cdot \mathrm{h}^{-1}$ ).

Literature review

a) In two class IV studies using full polysomnography at home, the rate of technically acceptable recordings was over 95\% [157, 158]. Nasal pressure and thermistor signals had the most artefacts. Polygraphy with limited montage (airflow, respiratory effort, oximetry and electrocardiography) has also been used (class II and IV) [73, 159]. The sensitivity of ambulatory polysomnography or polygraphy for the diagnosis of OSAS was $\sim 90 \%$ (class II) $[73,160]$.

b) In children with adenotonsillar hypertrophy and/or obesity, an abnormal oximetry according to the McGill criteria corresponds to OSAS of at least moderate severity but a negative result does not exclude OSAS with certainty (class III) [152]. An abnormal oximetry in children with Down syndrome with clinical suspicion of obstructive SDB is frequent but it may reflect not only OSAS but also an elevated central apnoea index ( $\geqslant 2$ episodes $\cdot \mathrm{h}^{-1}$ ) (class IV) [161]. A child with negative/inconclusive oximetry undergoing adenotonsillectomy for SDB has a low risk of post-operative respiratory complications (class III) $[152,162]$. Normative values for oxygen desaturation index ( $\geqslant 3 \%$ drop) in healthy children have been provided in a class III study [135]. Oxygen desaturation $(\geqslant 4 \%)$ of haemoglobin index $>2$ episodes $\cdot \mathrm{h}^{-1}$ in children with snoring may be a predictor of AHI $>1$ episode $\cdot h^{-1}$ in polysomnography (class III) [163].

c) Pulse transit time is the interval between the $\mathrm{R}$ wave of the electrocardiogram and the arrival of the photoplethysmographic pulse at the finger. Published evidence supporting its use is limited (class III-IV) $[164,165]$.

d) Low sensitivity and specificity for diagnosing OSAS by the OSAS score were found in a meta-analysis [166]. A class III study has demonstrated low sensitivity and specificity of OSA-18 score of $>60$ for predicting AHI $>1$ episode $\cdot h^{-1}[167]$.

e) The Paediatric Sleep Questionnaire is a useful instrument since it may predict OSAS-related neurobehavioural morbidity and its improvement after adenotonsillectomy better than the AHI, but its sensitivity and specificity for diagnosing OSAS are $78 \%$ and $72 \%$, respectively (class I and II) [168].

f) A total score $\geqslant 6.5$ on the Sleep Clinical Record is considered positive for OSAS with a sensitivity of $96.05 \%$ and a specificity of $67 \%$ for an AHI $>1$ episode $\cdot h^{-1}$ (class IV) [169].

Step 5: indications for treatment of obstructive SDB

5.1. In which cases and why is obstructive SDB usually treated?

Summary

a) An AHI $>5$ episodes $\cdot \mathrm{h}^{-1}$ has been used as an indication for treatment irrespective of the presence of morbidity but lower cut-off values have also been applied (obstructive AHI $\geqslant 2$ episodes $^{-1}{ }^{-1}$ and/or obstructive apnoea index $>1$ episode $\cdot h^{-1}$ ).

b) If AHI is 1-5 episodes $\cdot h^{-1}$, treatment has been shown to be beneficial especially in the presence of: morbidity from the cardiovascular system; morbidity from the central nervous system; enuresis; somatic growth delay or growth failure; decreased quality of life; or risk factors for persistence of SDB. The effect of treatment on excessive daytime sleepiness, hyperactivity/inattention, academic difficulties and cognitive 
deficits is modest at best and it is predicted by the severity of symptoms prior to treatment and not by the pretreatment AHI. The frequency of enuresis decreases and weight and height percentiles increase even in obese children.

c) In the context of clinical suspicion of obstructive SDB and if polysomnography is not available, treatment is considered when an alternative diagnostic method indicates OSAS or in the presence of SDB-associated morbidity.

\section{Literature review}

a) Nonrandomised, uncontrolled studies which included children who underwent surgical resection of adenoids and/or tonsils with a mean preoperative AHI of $6.4-69.3$ episodes $\cdot h^{-1}$ were reviewed in two meta-analyses [170, 171]. After adenotonsillectomy, AHI decreased. In the CHAT study, a subgroup of children with mild OSAS (i.e. obstructive AHI $\geqslant 2$ episodes $\cdot \mathrm{h}^{-1}$ or obstructive apnoea index $>1$ episode. $\mathrm{h}^{-1}$ but obstructive AHI $\leqslant 4.7$ episodes $\cdot \mathrm{h}^{-1}$ ) underwent adenotonsillectomy irrespective of the presence of morbidity (class I) [126]. However, due to the high frequency of spontaneous resolution of mild OSAS (65\%) over a follow-up period of 6 months, the number of children with mild disease needed to treat to prevent persistence of OSAS in one child was five. In contrast, the number of children with moderate-to-severe OSAS needed to treat to prevent persistence of disease in one was three. Thus, adenotonsillectomy is more efficacious regarding improvement in polysomnography parameters when offered to patients with an AHI $>5$ episodes $\cdot h^{-1}$.

b) In a retrospective, cohort study, 445 children with mild OSAS were treated with an intranasal corticosteroid and oral montelukast for at least 12 weeks and had follow-up polysomnography (class IV) [172]. OSAS resolved (obstructive AHI $<1$ episode $\cdot h^{-1}$ ) in $62 \%$ of treated children, a rate similar to the spontaneous resolution rate of mild OSAS in the CHAT study. The health benefits of lowering an AHI of 1-5 episodes $\cdot \mathrm{h}^{-1}$ to $<1$ episode $\cdot \mathrm{h}^{-1}$ are unclear, unless there is OSAS-associated morbidity or risk factors for OSAS persistence in the long-term.

The effects of adenotonsillectomy on cardiovascular parameters in children with OSAS have been evaluated in studies of low methodological quality (class III or IV), which have been summarised in two systematic reviews and in one systematic review/meta-analysis, and have also been evaluated in the CHAT study (class I) [85, 173-175]. A decrease in pulmonary artery pressure and improvement in echocardiographic parameters of cardiac structure and function were reported. The effects on blood pressure were not consistent in all studies but overall reduced levels were recorded after OSAS resolution. In the CHAT study, for each 5 episodes $\cdot \mathrm{h}^{-1}$ improvement in the AHI and $5 \mathrm{mmHg}$ reduction in the peak end-tidal carbon dioxide there was a reduction in heart rate of 1 and 1.5 beats per min, respectively (class I) [85].

In one class II study a reduction in sleepiness following adenotonsillectomy for mild-to-moderate OSAS was found [176]. Adenotonsillectomy was associated with moderately decreased attention-deficit and hyperactivity disorder symptoms at 2-13 months post-operatively including cases of mild OSAS (meta-analysis) [145]. In the CHAT study, changes in the attention and executive function objective scores from baseline to follow-up did not differ between the early-adenotonsillectomy and the watchful-waiting study groups (class I) [126]. However, there was a significant improvement in executive functioning, attention, behaviour and excessive daytime sleepiness as rated by parents, which was predicted by the preoperative severity of symptoms but not by the AHI (class I) [113, 177]. Similarly, two systematic reviews of mostly class III and IV studies concluded that adenotonsillectomy is followed by improvements in behavioural problems and neurocognitive skills irrespective of SDB severity $[178,179]$.

A systematic review highlighted the beneficial effect of adenotonsillectomy as a treatment for OSAS on the prevalence of enuresis even in children with mild disease [109].

In a systematic review and meta-analysis, pooled data from 10 studies of children with SDB and adenotonsillar hypertrophy are consistent with significant increases in weight and height z-scores post-operatively [110]. The increase in BMI z-score is positively associated with the AHI prior to adenotonsillectomy (class I) [180]. Obese children with adenotonsillar hypertrophy and OSAS are at risk of accelerated weight gain after adenotonsillectomy and OSAS recurrence (class I and III) [180, 181].

Two meta-analyses have reviewed evidence of low methodological quality demonstrating improvement in parameters of quality of life after adenotonsillectomy $[111,178]$. In the CHAT study, improvement in quality of life and symptom severity measures following adenotonsillectomy correlated weakly with changes in polysomnography parameters and was not influenced significantly by the baseline OSAS severity (class I) [113]. Rapid maxillary expansion was accompanied by an improvement in quality of life in children at high risk of OSAS (class IV) [182]. 
Treatment has been shown to be beneficial to children at risk of persistent OSAS (male sex, obese, with persistent tonsillar hypertrophy) (class I and III) [126, 127, 183].

c) A positive respiratory polygraphy or nocturnal oximetry in the context of clinical symptoms indicative of obstructive SDB has been used as an indication for adenotonsillectomy (class III or IV) [136, 162, 184]. Results of the CHAT study indicate that improvements in morbidity from the central nervous system, quality of life and symptoms of SDB occur post-adenotonsillectomy regardless of the severity of abnormalities in preoperative polysomnography (class I) $[113,177]$.

\subsection{Is the treatment of primary snoring beneficial?}

Summary

It is unclear whether or not children with primary snoring benefit from treatment interventions.

\section{Literature review}

Although there is evidence that primary snoring is accompanied by elevated nocturnal diastolic blood pressure, cognitive deficits and behavioural abnormalities, there are no studies addressing the efficacy of treatment interventions $[147,148]$.

\subsection{Are there conditions predisposing to upper airway obstruction which make treatment of obstructive SDB a priority?}

Summary

a) Major craniofacial abnormalities

b) Neuromuscular disorders

c) Achondroplasia

d) Chiari malformation

e) Down syndrome

f) Mucopolysaccharidoses

g) Prader-Willi syndrome

\section{Literature review}

a) Patients with syndromic craniosynostosis and OSAS are at risk for pulmonary hypertension and they may benefit from interventions including adenotonsillectomy (class IV) $[185,186]$.

b) Children with Duchenne muscular dystrophy and nocturnal hypoxaemia not receiving treatment for SDB are at risk of pulmonary hypertension (class IV) [89]. Patients with cerebral palsy and OSAS have improvements in symptoms and quality of life when CPAP, adenotonsillectomy or other surgical interventions are implemented to relieve upper airway obstruction compared with untreated children (class IV) [187-189].

c) Class III or IV studies have demonstrated high prevalence of OSAS, central apnoeas or central hypoventilation, and pulmonary hypertension in children with achondroplasia and improvement after adenotonsillectomy, weight loss, CPAP, NPPV or surgical dorsal decompression of the craniovertebral junction $[42-44,190,191]$.

d) Posterior fossa decompression may improve central and obstructive respiratory events, but NPPV is frequently necessary $[46,192]$.

e) Children with Down syndrome and OSAS are at risk of arterial pulmonary hypertension (class IV) [87, 88]. They are less likely to respond to adenotonsillectomy compared with children with OSAS but without Down syndrome and may require oxygen administration, CPAP or NPPV (class III or IV) [193, 194]. Other interventions include maxillary or midface advancement, tonsillar pillar plication, anterior tongue reduction, tongue-hyoid advancement, uvulopalatopharyngoplasty, laryngotracheoplasty and tracheostomy (class IV) [87, 88].

f) Children with mucopolysaccharidoses have high prevalence of OSAS which may be complicated by pulmonary hypertension. Adenotonsillectomy and enzyme replacement therapy may decrease OSAS severity $[54,55]$.

g) The majority of children with Prader-Willi syndrome have OSAS, mainly of mild severity and without reported symptoms [57]. Response to adenotonsillectomy is less favourable compared with children with OSAS but without Prader-Willi syndrome [57]. Nocturnal hypoxaemia is common even if OSAS is not 
present [195]. Growth hormone has been used to increase lean tissue mass and growth velocity, but severe OSAS may develop within 6 weeks after initiation of treatment $[196,197]$.

\subsection{Are children at risk for obstructive SDB but with negative polysomnography usually re-evaluated? \\ Summary}

Children with primary snoring may need re-evaluation annually since those who are overweight/obese may develop OSAS.

\section{Literature review}

Some children with primary snoring may develop OSAS in the long-term (class I and IV) $[125,198]$.

\section{Step 6: stepwise treatment approach for obstructive SDB}

6.1. Is there evidence that treatment interventions for obstructive SDB in childhood should follow

a stepwise approach?

Summary

Treatment interventions are applied in a stepwise fashion until complete resolution of SDB. Depending on the severity and underlying conditions predisposing to upper airway obstruction during sleep different treatment modalities are often combined.

\section{Literature review}

The appropriate sequence of treatment interventions for children with SDB has not been studied extensively. In a small prospective, cohort study, children with OSAS, enlarged tonsils and narrow maxillary complex were treated with either adenotonsillectomy followed by rapid maxillary expansion or vice versa (class II). Both procedures were necessary to achieve an AHI $<1$ episode. ${ }^{-1}$ [199].

\subsection{What are the indications and efficacy of weight loss in children with obstructive SDB?}

Summary

Massive weight loss ( $>0.5$ decrease in BMI $\mathrm{z}$-score) is an effective treatment intervention for OSAS in obese adolescents but there is no evidence regarding the efficacy of weight loss in overweight or obese children.

\section{Literature review}

Limited data from retrospective cohort studies generated from residential treatment centres or reports on bariatric surgery support this recommendation (class IV) [200-202]. The effects of weight loss on an outpatient basis have not been studied. There are no studies for the efficacy of weight loss as a treatment intervention for OSAS in young obese children.

\subsection{What are the indications, efficacy and potential complications of nasal corticosteroids or montelukast in children with obstructive SDB? \\ Summary}

a) Nasal corticosteroids and/or montelukast administered for 6-12 weeks have been shown to decrease the severity of mild-to-moderate OSAS with a less favourable response in children who are obese or older than 6 years.

b) There are no data regarding improvement of SDB-related morbidity after treatment with nasal corticosteroids or montelukast.

c) Use of nasal corticosteroids has been considered from the age of 2 years. Montelukast is well-tolerated.

\section{Literature review}

a-c) The efficacy of montelukast or nasal corticosteroids in mild or mild-to-moderate OSAS has been explored by three class I studies [203-205] and one class IV study [206]. The favourable effects of a 12-week combination of intranasal corticosteroid with oral montelukast for mild OSAS have been evaluated (class IV), but the frequency of OSAS resolution did not differ from that of untreated children in the CHAT study $[126,172]$. Beneficial effects of intranasal corticosteroid and montelukast may be due to reduction of the adenoidal size (meta-analysis, class I and IV) [206-208]. The long-term efficacy and side-effects of these medications have not been studied and this is a limiting factor in their use for many healthcare providers. Further research is necessary regarding the long-term efficacy and safety of montelukast and intranasal corticosteroids [209, 210]. 


\subsection{What are the indications, efficacy and potential complications of adenotonsillectomy in} children with obstructive SDB?

Summary

a) Adenotonsillectomy is indicated in children with OSAS and adenotonsillar hypertrophy, and most improvement in polysomnography abnormalities occurs in those with an AHI $>5$ episodes $\cdot \mathrm{h}^{-1}$. In otherwise healthy, non-obese children, the success rate of adenotonsillectomy (AHI $<1$ episode $^{-1} \mathrm{~h}^{-1}$ ) is $\sim 75 \%$. OSAS may recur after the initial post-operative improvement.

b) Risk factors for OSAS persistence post-adenotonsillectomy include: severe OSAS, obesity, history of asthma, inferior turbinate hypertrophy, nasal septum deviation, Mallampati score 3 or 4, retro-position of the mandible, syndromic craniosynostosis (midface hypoplasia), Down syndrome, achondroplasia, cerebral palsy and Prader-Willi syndrome.

c) Adenotonsillectomy is accompanied by improvements in quality of life, symptoms of SDB and SDB-associated morbidity (i.e. growth delay, frequency of enuresis, pulmonary hypertension, cor pulmonale, increased heart rate and morbidity from the central nervous system).

d) Dehydration, nausea and vomiting are minor complications, and local bleeding and upper airway obstruction are major complications. Risk factors for post-operative upper airway compromise include: AHI $>26$ episodes $\cdot h^{-1}$, oximetry recording with three or more clusters of desaturation $(\leqslant 4 \%)$ events and at least three desaturations to $<90 \%$, age $<3$ years, obesity or low weight, and neuromuscular, craniofacial or genetic disorders. Children with one or more risk factors are usually hospitalised for close monitoring for at least one night after adenotonsillectomy.

e) Some evidence suggests that the combination of an intranasal corticosteroid and oral montelukast for 12 weeks for persistent OSAS after adenotonsillectomy may be efficacious.

\section{Literature review}

a) Supporting evidence includes two meta-analyses [170, 171], one retrospective multicentre study (class IV) [156] and one randomised controlled multicentre trial (class I) [126]. Most improvement in AHI occurs among children with an AHI $>5$ episodes $\cdot h^{-1}$ (class I and III) $[126,211]$. A class IV prospective, cohort study has provided evidence for potential OSAS recurrence within 3 years after adenotonsillectomy [212].

b) AHI $>4.7$ episodes $\cdot \mathrm{h}^{-1}$ and obesity are significant risk factors for residual OSAS post-adenotonsillectomy (class I and IV, and meta-analysis) $[126,156,213]$. Efficacy of adenotonsillectomy is modest in children with SDB and craniofacial abnormalities and/or neuromuscular disorders (class IV) $[44,185,188,193,194$, 214-216].

c) Quality of life improves post-adenotonsillectomy (class I and III, meta-analysis and systematic review) $[111,113,126,178,211,217,218]$. Evidence for the increase in growth rate and resolution of enuresis has been presented in two systematic reviews and in the CHAT study (class I) [109, 110, 180]. Right ventricular function improves, and pulmonary artery pressure and mean heart rate decrease post-operatively (class I and IV) $[85,86,219,220]$. In the CHAT study, changes in the attention and executive function objective scores from baseline to follow-up did not differ between the early-adenotonsillectomy and the watchful-waiting groups but there were significant gains in executive functioning, attention, behaviour and daytime sleepiness as rated by parents (class I) $[126,177]$. Both the CHAT study and older low quality evidence have demonstrated that the favourable changes in sleepiness, behavioural problems, attention-deficit, hyperactivity symptoms, neurocognitive skills, quality of life scores and symptoms of SDB following adenotonsillectomy are not related to the preoperative severity of obstructive SDB (systematic reviews and class I-II) $[113,176-179,221]$. In contrast, the increase in BMI z-score is positively related to the preoperative AHI (class I) [180].

d) Subgroups of children with OSAS are at increased risk of respiratory complications following adenotonsillectomy (6.4\% to $27 \%)$ and the risk factors have been described in class II-IV studies [151, $152,154,222,223]$. However, school-aged children without comorbidities in the CHAT study had a very low frequency of respiratory complications post-adenotonsillectomy (1.4\%), which was not predicted by the severity of OSAS (class I) [155]. The frequency of local bleeding has been reported to be $3 \%$ or less, while the rate of post-operative nausea and vomiting is very low with the use of prophylactic anti-emetic medications such as dexamethasone (clinical practice guideline and class I study) [155, 224].

e) One retrospective cohort study evaluated the efficacy of an intranasal corticosteroid combined with oral montelukast for persistent OSAS post-operatively (class IV) [225]. Myofunctional re-education by nasal and oropharyngeal exercises has been implemented following adenotonsillectomy to treat residual OSAS or to prevent its recurrence but the published evidence involves only two studies of low methodological quality (class III and IV) [226, 227]. Orofacial muscular training is used to: prevent tongue and orofacial 
muscles hypotonia; encourage their appropriate position during wakefulness and sleep; re-establish nasal breathing; and eliminate mouth-breathing and pharyngeal airway obstruction [228].

\subsection{Is adenotonsillectomy more efficacious than adenoidectomy or tonsillectomy alone in terms of decreasing severity of obstructive SDB? \\ Summary}

There are no available, well-designed studies comparing the efficacy of isolated adenoidectomy or tonsillectomy to adenotonsillectomy in children with OSAS.

\section{Literature review}

The risk of future tonsillectomy following adenoidectomy decreases with age, and increases with tonsillar size at the time of adenoidectomy (class III) [229]. Surgical reduction of tonsillar volume (partial tonsillectomy or tonsilloplasty) has been used instead of complete tonsillectomy to reduce intraoperative and post-operative complications (class III and meta-analysis) [230, 231].

\subsection{What are the indications, efficacy and potential complications of rapid maxillary expansion} and orthodontic appliances?

Summary

a) Rapid maxillary expansion has been applied in children with OSAS and maxillary constriction.

b) Custom-made oral appliances have been used in cases of OSAS with retrognathia or malocclusion, and the related complications are minor (excessive salivation).

\section{Literature review}

a, b) Rapid maxillary expansion is associated with a decrease in AHI and improvement in quality of life (class IV) $[182,232]$. A Cochrane review including only one study concluded that oral appliances are an auxiliary treatment in children with OSAS and non-syndromic craniofacial abnormalities [233].

\subsection{What are the indications, efficacy and potential complications of CPAP or NPPV in children} with obstructive SDB?

Summary

a) Usual indications for CPAP are: residual OSAS after adenotonsillectomy (AHI $>5$ episodes $\cdot \mathrm{h}^{-1}$ ) and OSAS related to obesity, craniofacial abnormalities or neuromuscular disorders. If nocturnal hypoventilation occurs (e.g. end-tidal carbon dioxide tension $\left(\mathrm{PCO}_{2}\right)>50 \mathrm{mmHg}$ for $>25 \%$ of total sleep time or peak end-tidal $\mathrm{PCO}_{2} \geqslant 55 \mathrm{mmHg}$ ) NPPV is preferred.

b) Positive airway pressure ventilation is accompanied by improvements in gas exchange, attention deficits, sleepiness, behaviour and quality of life.

c) Complications of CPAP and NPPV include: nasal congestion, rhinorrhoea, epistaxis, facial skin erythema related to the mask and midface retrusion.

d) Adherence to CPAP or NPPV should be monitored using the device software. Management of complications and behavioural modification may improve patient adherence.

\section{Literature review}

a) Indications for CPAP and NPPV are described in class IV studies [234-239].

b) In two class III controlled trials, positive effects of CPAP and NPPV on neurobehavioural outcomes, school performance and quality of life were demonstrated $[236,240]$.

c) Retrospective studies have reported adverse effects of positive airway pressure treatment in children with OSAS (class IV) [238, 241].

d) Objective patient adherence has been evaluated in class I-IV studies and may vary from low to quite high ( $>8 \mathrm{~h}$ per night for $>70 \%$ of patients) regardless of the use of CPAP or NPPV $[235,237,238,242-$ 244]. Factors associated with better patient adherence include the degree of improvement in the AHI, overall perception of benefits from treatment, family structure and maternal education (class IV) [237, 243, 245]. Behavioural intervention may increase patient adherence to CPAP or NPPV (class IV) [246]. 


\subsection{What are the indications, efficacy and potential complications of craniofacial surgery in} children with obstructive SDB?

Summary

a) Craniofacial surgery has been offered to children with syndromic craniofacial abnormalities to: expand the dimensions of the upper airway; improve respiratory complaints, polysomnography parameters and quality of life; and facilitate decannulation or avoid tracheostomy.

b) Complications are rare but severe (cerebrospinal fluid leak, wound site infection, hypertrophic scarring, pseudoarthrosis, palatine perforation, apertognathia and nerve injury).

c) Hyoid tongue suspension and skeletal expansion procedures may be helpful in children with cerebral palsy or Down syndrome, and craniofacial surgery might be attempted in non-syndromic midface hypoplasia with OSAS.

\section{Literature review}

a, b) In a systematic review summarising studies of low methodological quality (class IV), 95.6\% of patients with micrognathia and OSAS had complete or partial resolution of upper airway obstruction after mandibular distraction osteogenesis and $84.2 \%$ of children with tracheostomy were decannulated [247]. The success rate was lower in the presence of other abnormalities (e.g. laryngomalacia or subglottic stenosis) or central sleep apnoea. In a second systematic review, low quality evidence on the application of midface distraction osteogenesis for midface hypoplasia/retrusion was summarised [248]. The frequency of post-operative decannulation in children with tracheostomy was $65.7 \%$ and there were improvements in upper airway volume on imaging studies and in polysomnography indices.

c) Limited evidence suggests benefits with: tongue hyoid suspension and skeletal expansion procedures in patients with cerebral palsy or Down syndrome and OSAS; maxillary and mandibular expansion by distraction osteogenesis in children with non-syndromic craniofacial abnormalities who have OSAS (class III-IV) [249-252].

\subsection{What are the indications, efficacy and potential complications of tracheostomy in children with obstructive SDB? \\ Summary}

a) Tracheostomy has the highest efficacy in the treatment of obstructive SDB, when compared with other surgical interventions; it is usually used only in severe OSAS when other nonsurgical or surgical interventions have failed or are contraindicated.

b) When compared with other procedures tracheostomy is associated with worse quality of life and psychosocial development and higher morbidity.

c) Complications may be early- (pneumomediastinum, pneumothorax, wound infection and bleeding) and late-onset (granulation tissue formation, tracheocutaneous fistulae, laryngo-tracheal stenosis, and in rare cases, tracheoinnominate artery fistula, adverse effects on facial growth and delayed language skills acquisition). Respiratory infections are more common in children with tracheostomy. Cannula obstruction by mucus and accidental decannulation may be life-threatening.

\section{Literature review}

a-c) Indications and complications of tracheostomy have been summarised in a literature review [253]. In case series published after 1990, the mortality rate related to tracheostomy was $3 \%$ or less, while early complications occurred in up to $5 \%$ of patients and late complications (especially granulation tissue formation) in up to $40 \%$ of cases [253]. Inferior quality of life has been reported in children with Down syndrome, Pierre Robin sequence or neuromuscular disease and OSAS who had tracheostomy compared with those who had successful craniofacial surgery (class IV) [254].

\section{Step 7: follow-up, recognition and management of persistent SDB}

7.1. How soon after each treatment intervention is the child with obstructive SDB usually re-evaluated and what outcomes are monitored?

Summary

a) Outcomes that are usually monitored at clinic visits 6 weeks to 12 months after each treatment intervention include: symptoms, severity of SDB evaluated objectively, quality of life, morbidity from the cardiovascular and central nervous system, enuresis, and growth rate.

b) Polysomnography is the preferred objective method to detect residual OSAS after a treatment intervention. However, in settings where polysomnography is not available, alternative methods such as polygraphy, oximetry and capnography are considered. 
c) Polysomnography or polygraphy is repeated for children at risk of persistent OSAS after adenotonsillectomy, for those with persistent symptoms of SDB post-operatively or for patients with mild OSAS who were treated with a nasal corticosteroid and/or montelukast. Most studies have suggested repeating polysomnography or polygraphy at 6 weeks or longer after adenotonsillectomy or following a 12 -week course with montelukast and a nasal corticosteroid.

d) Polysomnography has been repeated following 12 months of rapid maxillary expansion or earlier if SDB symptoms persist and after 6-months treatment with an oral appliance.

e) Polysomnography or polygraphy are used to titrate CPAP or NPPV and are then repeated at least annually (or earlier if there is a clinical indication). Polysomnography without and with occlusion of a progressively downsized tracheostomy tube has been used to predict successful decannulation.

f) When persistent SDB is demonstrated based on symptoms and/or polysomnography, nasopharyngoscopy, drug-induced sleep endoscopy and MRI are sometimes utilised to identify additional upper airway abnormalities (e.g. laryngomalacia or adenoid regrowth).

\section{Literature review}

a) Persistent or recurrent symptoms of upper airway obstruction or SDB-related morbidity (e.g. enuresis) may be recognised during clinic visits at 6 weeks to 12 months after each treatment intervention (class IIIV, meta-analyses) [109, 110, 176, 181, 211, 217, 221, 236, 255].

b) Polysomnography has been recommended as the gold standard tool for the evaluation of response to treatment interventions by a task force of the AASM $[11,12]$.

c) At 6 weeks after adenotonsillectomy, AHI is significantly reduced, but at 1 year children may have recurrent OSAS especially those who are obese and/or have a rapid increase in BMI post-operatively (class II) [181]. Evidence regarding the performance of polysomnography after adenotonsillectomy is summarised in the systematic review on respiratory indications of polysomnography prepared by a task force of the AASM [11, 12]. A class IV study demonstrated improvement in AHI after completion of a 12-week regimen with montelukast and a nasal corticosteroid [172].

d) Class III or IV studies have used polysomnography for evaluating the efficacy of rapid maxillary expansion or orthodontic appliances [232, 256-258].

e) There is limited evidence about the optimal respiratory monitoring for children who receive CPAP or NPPV (class IV) [234, 239]. Titration of positive airway pressure is ideally performed by polysomnography $[234-236,239,259]$. Supporting studies have been summarised in a practice parameters document and a systematic review prepared by a task force of the AASM $[11,12]$. There are two other AASM documents on: titration of positive airway pressure in patients with OSAS and titration of NPPV in stable chronic hypoventilation syndrome $[260,261]$. In class IV studies, polysomnography has been proposed as a predictor of successful decannulation [262].

f) Adenoid regrowth has been demonstrated in $12.2 \%$ of non-obese children with OSAS at 1.5 years post-adenotonsillectomy using nasopharyngoscopy (class IV) [255]. Drug-induced sleep endoscopy in children with persistent SDB may demonstrate laryngomalacia, adenoidal tissue regrowth, tongue base obstruction and pharyngeal collapse (class III and IV) [69, 263-265]. MRI of the upper airway may reveal residual adenoid tissue in obese children with persistent OSAS following adenotonsillectomy (class IV) [266]. Regrowth of adenoidal tissue, glossoptosis, hypopharyngeal collapse, soft palate collapse and hypertrophic lingual tonsil are abnormalities that may be identified by cine MRI in children with Down syndrome and persistent SDB after adenotonsillectomy (class IV) [267, 268].

Topics for future research are listed in the online supplementary material.

\section{Acknowledgements}

We thank Thomy Tonia (ERS Methodologist; Institute of Social and Preventive Medicine, University of Bern, Switzerland) for critically reviewing the manuscript.

\section{References}

1 Kaditis A, Kheirandish-Gozal L, Gozal D. Algorithm for the diagnosis and treatment of pediatric OSA: a proposal of two pediatric sleep centers. Sleep Med 2012; 13: 217-227.

2 Katz ES, D'Ambrosio CM. Pathophysiology of pediatric obstructive sleep apnea. Proc Am Thorac Soc 2008; 5: 253-262.

3 American Thoracic Society. Standards and indications for cardiopulmonary sleep studies in children. Am J Respir Crit Care Med 1996; 153: 866-878.

4 Dayyat E, Kheirandish-Gozal L, Gozal D. Childhood obstructive sleep apnea: one or two distinct disease entities? Sleep Med Clin 2007; 2: 433-444. 

$242-252$.

6 Marcus CL, Brooks LJ, Draper KA, et al. Diagnosis and management of childhood obstructive sleep apnea syndrome. Pediatrics 2012; 130: e714-e755.

7 Marcus CL, Brooks LJ, Draper KA, et al. Diagnosis and management of childhood obstructive sleep apnea syndrome. Pediatrics 2012; 130: 576-584.

8 Royal College of Paediatrics and Child Health. Working Party on Sleep Physiology and Respiratory Contro Disorders in Childhood. Standards for Services for Children with Disorders of Sleep Physiology. London, Royal College of Paediatrics and Child Health, 2009.

9 Iber C, Ancoli-Israel S, Chesson A, et al. AASM Manual for the Scoring of Sleep and Associated Events: Rules, Terminology and Technical Specifications. 1st Edn. Westchester, Illinois, American Academy of Sleep Medicine, 2007.

10 Berry RB, Budhiraja R, Gottlieb DJ, et al. Rules for scoring respiratory events in sleep: update of the 2007 AASM Manual for the Scoring of Sleep and Associated Events. Deliberations of the Sleep Apnea Definitions Task Force of the American Academy of Sleep Medicine. J Clin Sleep Med 2012; 8: 597-619.

11 Wise MS, Nichols CD, Grigg-Damberger MM, et al. Executive summary of respiratory indications for polysomnography in children: an evidence-based review. Sleep 2011; 34: 389-398.

12 Aurora RN, Zak RS, Karippot A, et al. Practice parameters for the respiratory indications for polysomnography in children. Sleep 2011; 34: 379-388.

13 American Academy of Neurology. Clinical Practice Guideline Process Manual. St. Paul, American Academy of Neurology, 2011.

14 Goodwin JL, Kaemingk KL, Mulvaney SA, et al. Clinical screening of school children for polysomnography to detect sleep-disordered breathing - the Tucson children's assessment of sleep apnea study (TuCASA). J Clin Sleep Med 2005; 1: 247-254.

15 Brunetti L, Rana S, Lospalluti ML, et al. Prevalence of obstructive sleep apnea syndrome in a cohort of 1,207 children of southern Italy. Chest 2001; 120: 1930-1935.

16 Papaioannou G, Kambas I, Tsaoussoglou M, et al. Age-dependent changes in the size of adenotonsillar tissue in childhood: implications for sleep-disordered breathing. J Pediatr 2013; 162: 269-274.

17 Nolan J, Brietzke SE. Systematic review of pediatric tonsil size and polysomnogram-measured obstructive sleep apnea severity. Otolaryngol Head Neck Surg 2011; 144: 844-850.

18 Mitchell RB, Garetz S, Moore RH, et al. The use of clinical parameters to predict obstructive sleep apnea syndrome severity in children: the childhood adenotonsillectomy (CHAT) study randomized clinical trial. Otolaryngol Head Neck Surg 2015; 141: 130-136.

19 Howard NS, Brietzke SE. Pediatric tonsil size: objective vs subjective measurements correlated to overnight polysomnogram. Otolaryngol Head Neck Surg 2009; 140: 675-681.

20 Lin SY, Melvin TA, Boss EF, et al. The association between allergic rhinitis and sleep-disordered breathing in children: a systematic review. Int Forum Allergy Rhinol 2013; 3: 504-509.

21 Corbo GM, Forastiere F, Agabiti N, et al. Snoring in 9- to 15-year-old children: risk factors and clinical relevance. Pediatrics 2001; 108: 1149-1154.

22 Bixler EO, Vgontzas AN, Lin HM, et al. Sleep disordered breathing in children in a general population sample: prevalence and risk factors. Sleep 2009; 32: 731-736.

23 Kohler M, Lushington K, Couper R, et al. Obesity and risk of sleep related upper airway obstruction in Caucasian children. J Clin Sleep Med 2008; 4: 129-136.

24 Redline S, Tishler PV, Schluchter M, et al. Risk factors for sleep-disordered breathing in children. Associations with obesity, race, and respiratory problems. Am J Respir Crit Care Med 1999; 159: 1527-1532.

25 Goodwin JL, Kaemingk KL, Fregosi RF, et al. Clinical outcomes associated with sleep-disordered breathing in Caucasian and Hispanic children - the Tucson children's assessment of sleep apnea study (TuCASA). Sleep 2003; 26: 587-591.

26 Alonso-Alvarez ML, Cordero-Guevara JA, Teran-Santos J, et al. Obstructive sleep apnea in obese community-dwelling children: the NANOS study. Sleep 2014; 37: 943-949.

27 Verhulst SL, Schrauwen N, Haentjens D, et al. Sleep-disordered breathing in overweight and obese children and adolescents: prevalence, characteristics and the role of fat distribution. Arch Dis Child 2007; 92: 205-208.

28 Flores-Mir C, Korayem M, Heo G, et al. Craniofacial morphological characteristics in children with obstructive sleep apnea syndrome: a systematic review and meta-analysis. J Am Dent Assoc 2013; 144: 269-277.

29 Katyal V, Pamula Y, Martin AJ, et al. Craniofacial and upper airway morphology in pediatric sleep-disordered breathing: systematic review and meta-analysis. Am J Orthod Dentofacial Orthop 2013; 143: 20-30.

30 Akre H, Overland B, Asten P, et al. Obstructive sleep apnea in Treacher Collins syndrome. Eur Arch Otorhinolaryngol 2012; 269: 331-337.

31 de Jong T, Bannink N, Bredero-Boelhouwer HH, et al. Long-term functional outcome in 167 patients with syndromic craniosynostosis; defining a syndrome-specific risk profile. J Plast Reconstr Aesthet Surg 2010; 63: 1635-1641.

32 Maclean JE, Waters K, Fitzsimons D, et al. Screening for obstructive sleep apnea in preschool children with cleft palate. Cleft Palate Craniofac J 2009; 46: 117-123.

33 Robison JG, Otteson TD. Increased prevalence of obstructive sleep apnea in patients with cleft palate. Arch Otolaryngol Head Neck Surg 2011; 137: 269-274.

34 Rose E, Staats R, Thissen U, et al. Sleep-related obstructive disordered breathing in cleft palate patients after palatoplasty. Plast Reconstr Surg 2002; 110: 392-396.

35 Pinard JM, Azabou E, Essid N, et al. Sleep-disordered breathing in children with congenital muscular dystrophies. Eur J Paediatr Neurol 2012; 16: 619-624.

36 Kotagal S, Gibbons VP, Stith JA. Sleep abnormalities in patients with severe cerebral palsy. Dev Med Child Neurol 1994; 36: 304-311.

37 Khan Y, Heckmatt JZ. Obstructive apnoeas in Duchenne muscular dystrophy. Thorax 1994; 49: 157-161.

38 Suresh S, Wales P, Dakin C, et al. Sleep-related breathing disorder in Duchenne muscular dystrophy: disease spectrum in the paediatric population. J Paediatr Child Health 2005; 41: 500-503. 
Mellies U, Ragette R, Schwake C, et al. Daytime predictors of sleep disordered breathing in children and adolescents with neuromuscular disorders. Neuromuscul Disord 2003; 13: 123-128.

Jain SV, Horn PS, Simakajornboon N, et al. Obstructive sleep apnea and primary snoring in children with epilepsy. J Child Neurol 2013; 28: 77-82.

Miano S, Tabarrini A, Vitelli $\mathrm{O}$, et al. The cooccurrence of interictal discharges and seizures in pediatric sleep-disordered breathing. Epilepsy Behav 2013; 29: 508-512.

Afsharpaiman S, Sillence DO, Sheikhvatan M, et al. Respiratory events and obstructive sleep apnea in children with achondroplasia: investigation and treatment outcomes. Sleep Breath 2011; 15: 755-761.

Ednick M, Tinkle BT, Phromchairak J, et al. Sleep-related respiratory abnormalities and arousal pattern in achondroplasia during early infancy. J Pediatr 2009; 155: 510-515.

Sisk EA, Heatley DG, Borowski BJ, et al. Obstructive sleep apnea in children with achondroplasia: surgical and anesthetic considerations. Otolaryngol Head Neck Surg 1999; 120: 248-254.

Dhamija R, Wetjen NM, Slocumb NL, et al. The role of nocturnal polysomnography in assessing children with Chiari type I malformation. Clin Neurol Neurosurg 2013; 115: 1837-1841.

Khatwa U, Ramgopal S, Mylavarapu A, et al. MRI findings and sleep apnea in children with Chiari I malformation. Pediatr Neurol 2013; 48: 299-307.

Losurdo A, Dittoni S, Testani E, et al. Sleep disordered breathing in children and adolescents with Chiari malformation type I. J Clin Sleep Med 2013; 9: 371-377.

Alsaadi MM, Iqbal SM, Elgamal EA, et al. Sleep-disordered breathing in children with Chiari malformation type II and myelomeningocele. Pediatr Int 2012; 54: 623-626.

Fung E, Witmans M, Ghosh M, et al. Upper airway findings in children with Down syndrome on sleep nasopharyngoscopy: case-control study. J Otolaryngol Head Neck Surg 2012; 41: 138-144.

Shott SR, Amin R, Chini B, et al. Obstructive sleep apnea: should all children with Down syndrome be tested? Arch Otolaryngol Head Neck Surg 2006; 132: 432-436.

Marcus CL, Keens TG, Bautista DB, et al. Obstructive sleep apnea in children with Down syndrome. Pediatrics 1991; 88: 132-139.

de Miguel-Diez J, Villa-Asensi JR, Alvarez-Sala JL. Prevalence of sleep-disordered breathing in children with Down syndrome: polygraphic findings in 108 children. Sleep 2003; 26: 1006-1009.

Guilleminault C, Primeau M, Chiu HY, et al. Sleep-disordered breathing in Ehlers-Danlos syndrome: a genetic model of OSA. Chest 2013; 144: 1503-1511.

Mesolella M, Cimmino M, Cantone E, et al. Management of otolaryngological manifestations in mucopolysaccharidoses: our experience. Acta Otorhinolaryngol Ital 2013; 33: 267-272.

John A, Fagondes S, Schwartz I, et al. Sleep abnormalities in untreated patients with mucopolysaccharidosis type VI. Am J Med Genet A 2011; 155A: 1546-1551.

Lin HY, Chen MR, Lin CC, et al. Polysomnographic characteristics in patients with mucopolysaccharidoses. Pediatr Pulmonol 2010; 45: 1205-1212.

Sedky K, Bennett DS, Pumariega A. Prader Willi syndrome and obstructive sleep apnea: co-occurrence in the pediatric population. J Clin Sleep Med 2014; 10: 403-409.

Cohen M, Hamilton J, Narang I. Clinically important age-related differences in sleep related disordered breathing in infants and children with Prader-Willi syndrome. PLoS One 2014; 9: e101012.

Xu Z, Cheuk DK, Lee SL. Clinical evaluation in predicting childhood obstructive sleep apnea. Chest 2006; 130: $1765-1771$.

Brooks LJ, Stephens BM, Bacevice AM. Adenoid size is related to severity but not the number of episodes of obstructive apnea in children. J Pediatr 1998; 132: 682-686.

Li AM, Wong E, Kew J, et al. Use of tonsil size in the evaluation of obstructive sleep apnoea. Arch Dis Child 2002; 87: 156-159.

Bravo G, Ysunza A, Arrieta J, et al. Videonasopharyngoscopy is useful for identifying children with Pierre Robin sequence and severe obstructive sleep apnea. Int J Pediatr Otorhinolaryngol 2005; 69: 27-33.

Arens R, McDonough JM, Corbin AM, et al. Upper airway size analysis by magnetic resonance imaging of children with obstructive sleep apnea syndrome. Am J Respir Crit Care Med 2003; 167: 65-70.

Fregosi RF, Quan SF, Kaemingk KL, et al. Sleep-disordered breathing, pharyngeal size and soft tissue anatomy in children. J Appl Physiol 2003; 95: 2030-2038.

Cappabianca S, Iaselli F, Negro A, et al. Magnetic resonance imaging in the evaluation of anatomical risk factors for pediatric obstructive sleep apnoea-hypopnoea: a pilot study. Int J Pediatr Otorhinolaryngol 2013; 77: 69-75.

Rachmiel A, Aizenbud D, Pillar G, et al. Bilateral mandibular distraction for patients with compromised airway analyzed by three-dimensional CT. Int J Oral Maxillofac Surg 2005; 34: 9-18.

Morimoto N, Kitamura M, Kosuga M, et al. CT and endoscopic evaluation of larynx and trachea in mucopolysaccharidoses. Mol Genet Metab 2014; 112: 154-159.

Van Holsbeke C, Vos W, Van Hoorenbeeck K, et al. Functional respiratory imaging as a tool to assess upper airway patency in children with obstructive sleep apnea. Sleep Med 2013; 14: 433-439.

Truong MT, Woo VG, Koltai PJ. Sleep endoscopy as a diagnostic tool in pediatric obstructive sleep apnea. Int $J$ Pediatr Otorhinolaryngol 2012; 76: 722-727.

0 Monahan KJ, Larkin EK, Rosen CL, et al. Utility of noninvasive pharyngometry in epidemiologic studies of childhood sleep-disordered breathing. Am J Respir Crit Care Med 2002; 165: 1499-1503.

Raynes-Greenow CH, Hadfield RM, Cistulli PA, et al. Sleep apnea in early childhood associated with preterm birth but not small for gestational age: a population-based record analysis. Sleep 2012; 35: 1475-1480.

Paavonen EJ, Strang-Karlsson S, Raikkonen K, et al. Very low birth weight increases risk for sleep-disordered breathing in young adulthood: the Helsinki study of very low birth weight adults. Pediatrics 2007; 120: 778-784.

Rosen CL, Larkin EK, Kirchner HL, et al. Prevalence and risk factors for sleep-disordered breathing in 8- to 11-year-old children: association with race and prematurity. J Pediatr 2003; 142: 383-389.

Alexopoulos EI, Charitos G, Malakasioti G, et al. Parental history of adenotonsillectomy is associated with obstructive sleep apnea severity in children with snoring. J Pediatr 2014; 164: 1352-1357.

Kalampouka E, Moudaki A, Malakasioti G, et al. Family history of adenotonsillectomy as a risk factor for tonsillar hypertrophy and snoring in childhood. Pediatr Pulmonol 2014; 49: 366-371. 
Lundkvist K, Sundquist K, Li X, et al. Familial risk of sleep-disordered breathing. Sleep Med 2012; 13: 668-673. Friberg D, Sundquist J, Li X, et al. Sibling risk of pediatric obstructive sleep apnea syndrome and adenotonsillar hypertrophy. Sleep 2009; 32: 1077-1083.

Zintzaras E, Kaditis AG. Sleep-disordered breathing and blood pressure in children: a meta-analysis. Arch Pediatr Adolesc Med 2007; 161: 172-178.

$\mathrm{Xu} \mathrm{Z}$, Li B, Shen K. Ambulatory blood pressure monitoring in Chinese children with obstructive sleep apnea/ hypopnea syndrome. Pediatr Pulmonol 2013; 48: 274-279.

Horne RS, Yang JS, Walter LM, et al. Elevated blood pressure during sleep and wake in children with sleep-disordered breathing. Pediatrics 2011; 128: e85-e92.

Amin R, Somers VK, McConnell K, et al. Activity-adjusted 24-hour ambulatory blood pressure and cardiac remodeling in children with sleep disordered breathing. Hypertension 2008; 51: 84-91.

Li AM, Au CT, Sung RY, et al. Ambulatory blood pressure in children with obstructive sleep apnoea: a community based study. Thorax 2008; 63: 803-809.

Hannon TS, Tu W, Watson SE, et al. Morning blood pressure is associated with sleep quality in obese adolescents. J Pediatr 2014; 164: 313-317.

National High Blood Pressure Education Program Working Group. The fourth report on the diagnosis, evaluation, and treatment of high blood pressure in children and adolescents. Pediatrics 2004; 114: 555-576.

Quante M, Wang R, Weng J, et al. The effect of adenotonsillectomy for childhood sleep apnea on cardiometabolic measures. Sleep 2015; 38: 1395-1403.

Miman MC, Kirazli T, Ozyurek R. Doppler echocardiography in adenotonsillar hypertrophy. Int J Pediatr Otorhinolaryngol 2000; 54: 21-26.

Lefaivre JF, Cohen SR, Burstein FD, et al. Down syndrome: identification and surgical management of obstructive sleep apnea. Plast Reconstr Surg 1997; 99: 629-637.

Jacobs IN, Gray RF, Todd NW. Upper airway obstruction in children with Down syndrome. Arch Otolaryngol Head Neck Surg 1996; 122: 945-950.

Melacini P, Vianello A, Villanova C, et al. Cardiac and respiratory involvement in advanced stage Duchenne muscular dystrophy. Neuromuscul Disord 1996; 6: 367-376.

Khalyfa A, Serpero LD, Kheirandish-Gozal L, et al. TNF- $\alpha$ gene polymorphisms and excessive daytime sleepiness in pediatric obstructive sleep apnea. J Pediatr 2011; 158: 77-82.

Tsaoussoglou M, Bixler EO, Calhoun S, et al. Sleep-disordered breathing in obese children is associated with prevalent excessive daytime sleepiness, inflammation, and metabolic abnormalities. J Clin Endocrinol Metab 2010; 95: 143-150.

Melendres MC, Lutz JM, Rubin ED, et al. Daytime sleepiness and hyperactivity in children with suspected sleep-disordered breathing. Pediatrics 2004; 114: 768-775.

Goodwin JL, Babar SI, Kaemingk KL, et al. Symptoms related to sleep-disordered breathing in white and Hispanic children: the Tucson children's assessment of sleep apnea study. Chest 2003; 124: 196-203. 2001; 108: 693-697.

Gozal D, Kheirandish-Gozal L. Obesity and excessive daytime sleepiness in prepubertal children with obstructive sleep apnea. Pediatrics 2009; 123: 13-18.

Chervin RD, Weatherly RA, Ruzicka DL, et al. Subjective sleepiness and polysomnographic correlates in children scheduled for adenotonsillectomy $v s$ other surgical care. Sleep 2006; 29: 495-503.

Cortese S, Faraone SV, Konofal E, et al. Sleep in children with attention-deficit/hyperactivity disorder: meta-analysis of subjective and objective studies. J Am Acad Child Adolesc Psychiatry 2009; 48: 894-908.

Sadeh A, Pergamin L, Bar-Haim Y. Sleep in children with attention-deficit hyperactivity disorder: a meta-analysis of polysomnographic studies. Sleep Med Rev 2006; 10: 381-398.

Sedky K, Bennett DS, Carvalho KS. Attention deficit hyperactivity disorder and sleep disordered breathing in pediatric populations: a meta-analysis. Sleep Med Rev 2014; 18: 349-356.

Perfect MM, Archbold K, Goodwin JL, et al. Risk of behavioral and adaptive functioning difficulties in youth with previous and current sleep disordered breathing. Sleep 2013; 36: 517B-525B.

Brockmann PE, Urschitz MS, Schlaud M, et al. Primary snoring in school children: prevalence and neurocognitive impairments. Sleep Breath 2012; 16: 23-29.

Miano S, Paolino MC, Urbano A, et al. Neurocognitive assessment and sleep analysis in children with sleep-disordered breathing. Clin Neurophysiol 2011; 122: 311-319.

Calhoun SL, Mayes SD, Vgontzas AN, et al. No relationship between neurocognitive functioning and mild sleep disordered breathing in a community sample of children. J Clin Sleep Med 2009; 5: 228-234. outcomes at 4 and 7 years. Pediatrics 2012; 129: e857-e865.

Mulvaney SA, Goodwin JL, Morgan WJ, et al. Behavior problems associated with sleep disordered breathing in school-aged children - the Tucson children's assessment of sleep apnea study. J Pediatr Psychol 2006; 31: 322-330.

06 Alexopoulos EI, Malakasioti G, Varlami V, et al. Nocturnal enuresis is associated with moderate-to-severe obstructive sleep apnea in children with snoring. Pediatr Res 2014; 76: 555-559.

Barone JG, Hanson C, DaJusta DG, et al. Nocturnal enuresis and overweight are associated with obstructive sleep apnea. Pediatrics 2009; 124: e53-e59.

Brooks LJ, Topol HI. Enuresis in children with sleep apnea. J Pediatr 2003; 142: 515-518.

Jeyakumar A, Rahman SI, Armbrecht ES, et al. The association between sleep-disordered breathing and enuresis in children. Laryngoscope 2012; 122: 1873-1877.

Bonuck KA, Freeman K, Henderson J. Growth and growth biomarker changes after adenotonsillectomy: systematic review and meta-analysis. Arch Dis Child 2009; 94: 83-91.

Baldassari CM, Mitchell RB, Schubert C, et al. Pediatric obstructive sleep apnea and quality of life: a meta-analysis. Otolaryngol Head Neck Surg 2008; 138: 265-273.

Trasiuk A, Greenberg-Dotan S, Simon-Tuval T, et al. Elevated morbidity and health care use in children with obstructive sleep apnea syndrome. Am J Respir Crit Care Med 2007; 175: 55-61. 
113 Garetz SL, Mitchell RB, Parker PD, et al. Quality of life and obstructive sleep apnea symptoms after pediatric adenotonsillectomy. Pediatrics 2015; 135: e477-e486.

114 Gozal D, Kheirandish-Gozal L, Capdevila OS, et al. Prevalence of recurrent otitis media in habitually snoring school-aged children. Sleep Med 2008; 9: 549-554.

115 Malakasioti G, Gourgoulianis K, Chrousos G, et al. Interactions of obstructive sleep-disordered breathing with recurrent wheezing or asthma and their effects on sleep quality. Pediatr Pulmonol 2011; 46: 1047-1054.

116 Ross KR, Storfer-Isser A, Hart MA, et al. Sleep-disordered breathing is associated with asthma severity in children. J Pediatr 2012; 160: 736-742.

117 Kheirandish-Gozal L, Dayyat EA, Eid NS, et al. Obstructive sleep apnea in poorly controlled asthmatic children: effect of adenotonsillectomy. Pediatr Pulmonol 2011; 46: 913-918.

118 Bhattacharjee R, Choi BH, Gozal D, et al. Association of adenotonsillectomy with asthma outcomes in children: a longitudinal database analysis. PLoS Med 2014; 11: e1001753.

119 Redline S, Storfer-Isser A, Rosen CL, et al. Association between metabolic syndrome and sleep-disordered breathing in adolescents. Am J Respir Crit Care Med 2007; 176: 401-408.

120 Verhulst SL, Schrauwen N, Haentjens D, et al. Sleep-disordered breathing and the metabolic syndrome in overweight and obese children and adolescents. J Pediatr 2007; 150: 608-612.

121 Junqueira $\mathrm{P}$, Marchesan IQ, de Oliveira LR, et al. Speech-language pathology findings in patients with mouth breathing: multidisciplinary diagnosis according to etiology. Int J Orofacial Myology 2010; 36: 27-32.

122 Honaker SM, Gozal D, Bennett J, et al. Sleep-disordered breathing and verbal skills in school-aged community children. Dev Neuropsychol 2009; 34: 588-600.

123 Lundeborg I, McAllister A, Graf J, et al. Oral motor dysfunction in children with adenotonsillar hypertrophy-effects of surgery. Logoped Phoniatr Vocol 2009: 34: 111-116.

124 O'Brien LM, Mervis CB, Holbrook CR, et al. Neurobehavioral correlates of sleep-disordered breathing in children. J Sleep Res 2004; 13: 165-172.

$125 \mathrm{Li} \mathrm{AM}$, Zhu Y, Au CT, et al. Natural history of primary snoring in school-aged children: a 4-year follow-up study. Chest 2013; 143: 729-735.

126 Marcus CL, Moore RH, Rosen CL, et al. A randomized trial of adenotonsillectomy for childhood sleep apnea. N Engl J Med 2013; 368: 2366-2376.

127 Goodwin JL, Vasquez MM, Silva GE, et al. Incidence and remission of sleep-disordered breathing and related symptoms in 6- to 17-year old children - the Tucson children's assessment of sleep apnea study. J Pediatr 2010; 157: 57-61.

128 Li AM, Au CT, So HK, et al. Prevalence and risk factors of habitual snoring in primary school children. Chest 2010; 138: 519-527.

129 Hultcrantz E, Lofstrand Tidestrom B. The development of sleep disordered breathing from 4 to 12 years and dental arch morphology. Int J Pediatr Otorhinolaryngol 2009; 73: 1234-1241.

130 Roland PS, Rosenfeld RM, Brooks LJ, et al. Clinical practice guideline: polysomnography for sleep-disordered breathing prior to tonsillectomy in children. Otolaryngol Head Neck Surg 2011; 145: Suppl., S1-S15.

131 Accardo JA, Shults J, Leonard MB, et al. Differences in overnight polysomnography scores using the adult and pediatric criteria for respiratory events in adolescents. Sleep 2010; 33: 1333-1339.

132 Tapia IE, Karamessinis L, Bandla P, et al. Polysomnographic values in children undergoing puberty: pediatric $v s$. adult respiratory rules in adolescents. Sleep 2008; 31: 1737-1744.

133 O'Driscoll DM, Foster AM, Ng ML, et al. Central apnoeas have significant effects on blood pressure and heart rate in children. J Sleep Res 2009; 18: 415-421.

134 Baldassari CM, Kepchar J, Bryant L, et al. Changes in central apnea index following pediatric adenotonsillectomy. Otolaryngol Head Neck Surg 2012; 146: 487-490.

135 Scholle S, Wiater A, Scholle HC. Normative values of polysomnographic parameters in childhood and adolescence: cardiorespiratory parameters. Sleep Med 2011; 12: 988-996.

136 Saito H, Araki K, Ozawa $\mathrm{H}$, et al. Pulse-oximetery is useful in determining the indications for adeno-tonsillectomy in pediatric sleep-disordered breathing. Int J Pediatr Otorhinolaryngol 2007; 71: 1-6.

137 Verhulst SL, Schrauwen N, Haentjens D, et al. Reference values for sleep-related respiratory variables in asymptomatic European children and adolescents. Pediatr Pulmonol 2007; 42: 159-167.

138 Montgomery-Downs HE, O’Brien LM, Gulliver TE, et al. Polysomnographic characteristics in normal preschool and early school-aged children. Pediatrics 2006; 117: 741-753.

139 Traeger N, Schultz B, Pollock AN, et al. Polysomnographic values in children 2-9 years old: additional data and review of the literature. Pediatr Pulmonol 2005; 40: 22-30.

140 Fukumizu M, Kohyama J. Central respiratory pauses, sighs, and gross body movements during sleep in children. Physiol Behav 2004; 82: 721-726.

141 Uliel S, Tauman R, Greenfeld M, et al. Normal polysomnographic respiratory values in children and adolescents. Chest 2004; 125: 872-878.

142 Goh DY, Galster P, Marcus CL. Sleep architecture and respiratory disturbances in children with obstructive sleep apnea. Am J Respir Crit Care Med 2000; 162: 682-686.

143 Acebo C, Millman RP, Rosenberg C, et al. Sleep, breathing, and cephalometrics in older children and young adults. Part I - normative values Chest 1996; 109: 664-672.

144 Marcus CL, Omlin KJ, Basinki DJ, et al. Normal polysomnographic values for children and adolescents. Am Rev Respir Dis 1992; 146: 1235-1239.

145 Sedky K, Bennett DS, Carvalho KS. Attention deficit hyperactivity disorder and sleep disordered breathing in pediatric populations: a meta-analysis. Sleep Med Rev 2014; 18: 349-356.

146 Certal V, Nishino N, Camacho M, et al. Reviewing the systematic reviews in OSA surgery. Otolaryngol Head Neck Surg 2013; 149: 817-829.

147 Li AM, Au CT, Ho C, et al. Blood pressure is elevated in children with primary snoring. J Pediatr 2009; 155: 362-368.

148 Biggs SN, Nixon GM, Horne RS. The conundrum of primary snoring in children: what are we missing in regards to cognitive and behavioural morbidity? Sleep Med Rev 2014; 18: 463-475.

149 Chervin RD, Garetz SL, Ruzicka DL, et al. Do respiratory cycle-related EEG changes or arousals from sleep predict neurobehavioral deficits and response to adenotonsillectomy in children? J Clin Sleep Med 2014; 10: 903-911. 
Owens JA, Mehlenbeck R, Lee J, et al. Effect of weight, sleep duration, and comorbid sleep disorders on behavioral outcomes in children with sleep-disordered breathing. Arch Pediatr Adolesc Med 2008; 162: 313-321.

Jaryszak EM, Shah RK, Vanison CC, et al. Polysomnographic variables predictive of adverse respiratory events after pediatric adenotonsillectomy. Arch Otolaryngol Head Neck Surg 2011; 137: 15-18.

Nixon GM, Kermack AS, Davis GM, et al. Planning adenotonsillectomy in children with obstructive sleep apnea: the role of overnight oximetry. Pediatrics 2004; 113: e19-e25.

Wilson K, Lakheeram I, Morielli A, et al. Can assessment for obstructive sleep apnea help predict postadenotonsillectomy respiratory complications? Anesthesiology 2002; 96: 313-322.

Ye J, Liu H, Zhang G, et al. Postoperative respiratory complications of adenotonsillectomy for obstructive sleep apnea syndrome in older children: prevalence, risk factors, and impact on clinical outcome. J Otolaryngol Head Neck Surg 2009; 38: 49-58.

Konstantinopoulou S, Gallagher P, Elden L, et al. Complications of adenotonsillectomy for obstructive sleep apnea in school-aged children. Int J Pediatr Otorhinolaryngol 2015; 79: 240-245.

Bhattacharjee R, Kheirandish-Gozal L, Spruyt K, et al. Adenotonsillectomy outcomes in treatment of obstructive sleep apnea in children: a multicenter retrospective study. Am J Respir Crit Care Med 2010; 182: 676-683.

Goodwin JL, Enright PL, Kaemingk KL, et al. Feasibility of using unattended polysomnography in children for research - report of the Tucson children's assessment of sleep apnea study (TuCASA). Sleep 2001; 24: 937-944.

Marcus CL, Traylor J, Biggs SN, et al. Feasibility of comprehensive, unattended ambulatory polysomnography in school-aged children. J Clin Sleep Med 2014; 10: 913-918.

Moss D, Urschitz MS, von Bodman A, et al. Reference values for nocturnal home polysomnography in primary schoolchildren. Pediatr Res 2005; 58: 958-965.

Alonso-Alvarez ML, Teran-Santos J, Ordax Carbajo E, et al. Reliability of home respiratory polygraphy for the diagnosis of sleep apnea in children. Chest 2015; 147: 1020-1028.

Coverstone AM, Bird M, Sicard M, et al. Overnight pulse oximetry for evaluation of sleep apnea among children with trisomy 21. J Clin Sleep Med 2014; 10: 1309-1315.

Horwood L, Brouillette RT, McGregor CD, et al. Testing for pediatric obstructive sleep apnea when health care resources are rationed. J Otolaryngol Head Neck Surg 2014; 140: 616-623. syndrome in children. Int J Pediatr Otorhinolaryngol 2013; 77: 1286-1290. breathing. Arch Otolaryngol Head Neck Surg 2012; 138: 398-403.

Brietzke SE, Katz ES, Roberson DW. Pulse transit time as a screening test for pediatric sleep-related breathing disorders. Arch Otolaryngol Head Neck Surg 2007; 133: 980-984.

Schechter MS. Technical report: diagnosis and management of childhood obstructive sleep apnea syndrome. Pediatrics 2002; 109: e69.

Borgstrom A, Nerfeldt P, Friberg D. Questionnaire OSA-18 has poor validity compared to polysomnography in pediatric obstructive sleep apnea. Int J Pediatr Otorhinolaryngol 2013; 77: 1864-1868.

Chervin RD, Weatherly RA, Garetz SL, et al. Pediatric sleep questionnaire: prediction of sleep apnea and outcomes. Arch Otolaryngol Head Neck Surg 2007; 133: 216-222.

Villa MP, Paolino MC, Castaldo R, et al. Sleep clinical record: an aid to rapid and accurate diagnosis of paediatric sleep disordered breathing. Eur Respir J 2013; 41: 1355-1361.

Friedman M, Wilson M, Lin HC, et al. Updated systematic review of tonsillectomy and adenoidectomy for treatment of pediatric obstructive sleep apnea/hypopnea syndrome. Otolaryngol Head Neck Surg 2009; 140: 800-808.

Brietzke SE, Gallagher D. The effectiveness of tonsillectomy and adenoidectomy in the treatment of pediatric obstructive sleep apnea/hypopnea syndrome: a meta-analysis. Otolaryngol Head Neck Surg 2006; 134: 979-984.

Kheirandish-Gozal L, Bhattacharjee
children. Chest 2014; 146: 88-95.

Weber SAT, Pierri Carvalho R, Ridley G, et al. A systematic review and meta-analysis of cohort studies of echocardiographic findings in OSA children after adenotonsilectomy. Int J Pediatr Otorhinolaryngol 2014; 78: 1571-1578.

4 Teo DT, Mitchell RB. Systematic review of effects of adenotonsillectomy on cardiovascular parameters in children with obstructive sleep apnea. Otolaryngol Head Neck Surg 2013; 148: 21-28.

Vlahandonis A, Walter LM, Horne RS. Does treatment of SDB in children improve cardiovascular outcome? Sleep Med Rev 2013; 17: 75-85.

Chervin RD, Ruzicka DL, Giordani BJ, et al. Sleep-disordered breathing, behavior, and cognition in children before and after adenotonsillectomy. Pediatrics 2006; 117: e769-e778. Rosen CL, Wang R, Taylor HG, et al. Utility of
apnea syndrome. Pediatrics 2015; 135: e662-e671.

Garetz SL. Behavior, cognition, and quality of life after adenotonsillectomy for pediatric sleep-disordered breathing: summary of the literature. Otolaryngol Head Neck Surg 2008; 138: S19-S26.

Kohler MJ, Lushington K, Kennedy JD. Neurocognitive performance and behavior before and after treatment for sleep-disordered breathing in children. Nat Sci Sleep 2010; 2: 159-185.

Katz ES, Moore RH, Rosen CL, et al. Growth after adenotonsillectomy for obstructive sleep apnea: an RCT. Pediatrics 2014; 134: 282-289.

Amin R, Anthony L, Somers V, et al. Growth velocity predicts recurrence of sleep-disordered breathing 1 year after adenotonsillectomy. Am J Respir Crit Care Med 2008; 177: 654-659.

Katyal V, Pamula Y, Daynes CN, et al. Craniofacial and upper airway morphology in pediatric sleep-disordered breathing and changes in quality of life with rapid maxillary expansion. Am J Orthod Dentofacial Orthop 2013; 144: 860-871.

3 Li AM, Au CT, Ng SK, et al. Natural history and predictors for progression of mild childhood obstructive sleep apnoea. Thorax 2010; 65: 27-31.

Certal V, Camacho M, Winck JC, et al. Unattended sleep studies in pediatric OSA: a systematic review and meta-analysis. Laryngoscope 2015; 125: 255-262. 
Amonoo-Kuofi K, Phillips SP, Randhawa PS, et al. Adenotonsillectomy for sleep-disordered breathing in children with syndromic craniosynostosis. I Craniofac Surg 2009; 20: 1978-1980.

Spier S, Rivlin J, Rowe RD, et al. Sleep in Pierre Robin syndrome. Chest 1986; 90: 711-715.

Hsiao KH, Nixon GM. The effect of treatment of obstructive sleep apnea on quality of life in children with cerebral palsy. Res Dev Disabil 2008; 29: 133-140.

Magardino TM, Tom LW. Surgical management of obstructive sleep apnea in children with cerebral palsy. Laryngoscope 1999; 109: 1611-1615.

Cohen SR, Lefaivre JF, Burstein FD, et al. Surgical treatment of obstructive sleep apnea in neurologically compromised patients. Plast Reconstr Surg 1997; 99: 638-646.

Julliand S, Boule M, Baujat G, et al. Lung function, diagnosis, and treatment of sleep-disordered breathing in children with achondroplasia. Am J Med Genet A 2012; 158A: 1987-1993.

Tasker RC, Dundas I, Laverty A, et al. Distinct patterns of respiratory difficulty in young children with achondroplasia: a clinical, sleep, and lung function study. Arch Dis Child 1998; 79: 99-108.

Addo NK, Javadpour S, Kandasamy J, et al. Central sleep apnea and associated Chiari malformation in children with syndromic craniosynostosis: treatment and outcome data from a supraregional national craniofacial center. J Neurosurg Pediatr 2013; 11: 296-301.

Merrell JA, Shott SR. OSAS in Down syndrome: T\&A versus T\&A plus lateral pharyngoplasty. Int J Pediatr Otorhinolaryngol 2007; 71: 1197-1203.

Shete MM, Stocks RMS, Sebelik ME, et al. Effects of adeno-tonsillectomy on polysomnography patterns in Down syndrome children with obstructive sleep apnea: a comparative study with children without Down syndrome. Int J Pediatr Otorhinolaryngol 2010; 74: 241-244.

Vandeleur M, Davey MJ, Nixon GM. Are sleep studies helpful in children with Prader-Willi syndrome prior to commencement of growth hormone therapy? J Paediatr Child Health 2013; 49: 238-241.

Al-Saleh S, Al-Naimi A, Hamilton J, et al. Longitudinal evaluation of sleep-disordered breathing in children with Prader-Willi syndrome during 2 years of growth hormone therapy. J Pediatr 2013; 162: 263-268.

Tauber M, Diene G, Molinas C, et al. Review of 64 cases of death in children with Prader-Willi syndrome (PWS). Am J Med Genet A 2008; 146A: 881-887.

Marcus CL, Hamer A, Loughlin GM. Natural history of primary snoring in children. Pediatr Pulmonol 1998; 26 : 6-11. Guilleminault C, Monteyrol P-J, Huynh NT, et al. Adeno-tonsillectomy and rapid maxillary distraction in pre-pubertal children, a pilot study. Sleep Breath 2011; 15: 173-177.

Verhulst SL, Franckx H, Van Gaal L, et al. The effect of weight loss on sleep-disordered breathing in obese teenagers. Obesity (Silver Spring) 2009; 17: 1178-1183.

Kalra M, Inge T, Garcia V, et al. Obstructive sleep apnea in extremely overweight adolescents undergoing bariatric surgery. Obes Res 2005; 13: 1175-1179.

Siegfried W, Siegfried A, Rabenbauer M, et al. Snoring and sleep apnea in obese adolescents: effect of long-term weight loss-rehabilitation. Sleep Breath 1999; 3: 83-88.

Goldbart AD, Greenberg-Dotan S, Tal A. Montelukast for children with obstructive sleep apnea: a double-blind, placebo-controlled study. Pediatrics 2012; 130: e575-e580.

Kheirandish-Gozal L, Gozal D. Intranasal budesonide treatment for children with mild obstructive sleep apnea syndrome. Pediatrics 2008; 122: e149-e155.

Brouillette RT, Manoukian JJ, Ducharme FM, et al. Efficacy of fluticasone nasal spray for pediatric obstructive sleep apnea. J Pediatr 2001; 138: 838-844.

Goldbart AD, Goldman JL, Veling MC, et al. Leukotriene modifier therapy for mild sleep-disordered breathing in children. Am J Respir Crit Care Med 2005; 172: 364-370.

Zhang L, Mendoza-Sassi RA, Cesar JA, et al. Intranasal corticosteroids for nasal airway obstruction in children with moderate to severe adenoidal hypertrophy. Cochrane Database Syst Rev 2008; 3: CD006286.

Berlucchi M, Salsi D, Valetti L, et al. The role of mometasone furoate aqueous nasal spray in the treatment of adenoidal hypertrophy in the pediatric age group: preliminary results of a prospective, randomized study. Pediatrics 2007; 119: e1392-e1397.

9 Kuhle S, Urschitz MS. Anti-inflammatory medications for obstructive sleep apnea in children. Cochrane Database Syst Rev 2011; 1: CD007074.

Brozek JL, Bousquet J, Baena-Cagnani CE, et al. Allergic rhinitis and its impact on asthma (ARIA) guidelines: 2010 revision. J Allergy Clin Immunol 2010; 126: 466-476.

1 Volsky PG, Woughter MA, Beydoun HA, et al. Adenotonsillectomy vs observation for management of mild obstructive sleep apnea in children. Otolaryngol Head Neck Surg 2014; 150: 126-132.

2 Huang YS, Guilleminault C, Lee LA, et al. Treatment outcomes of adenotonsillectomy for children with obstructive sleep apnea: a prospective longitudinal study. Sleep 2014; 37: 71-76.

13 Costa DJ, Mitchell R. Adenotonsillectomy for obstructive sleep apnea in obese children: a meta-analysis. Otolaryngol Head Neck Surg 2009; 140: 455-460.

4 Guilleminault C, Huang YS, Glamann C, et al. Adenotonsillectomy and obstructive sleep apnea in children: a prospective survey. Otolaryngol Head Neck Surg 2007; 136: 169-175.

Kerschner JE, Lynch JB, Kleiner H, et al. Uvulopalatopharyngoplasty with tonsillectomy and adenoidectomy as a treatment for obstructive sleep apnea in neurologically impaired children. Int J Pediatr Otorhinolaryngol 2002; 62: 229-235.

16 Pavone M, Paglietti MG, Petrone A, et al. Adenotonsillectomy for obstructive sleep apnea in children with Prader-Willi syndrome. Pediatr Pulmonol 2006; 41: 74-79.

7 Lee CH, Kang KT, Weng WC, et al. Quality of life after adenotonsillectomy for children with sleep-disordered breathing: a linear mixed model analysis. Int J Pediatr Otorhinolaryngol 2014; 78: 1374-1380.

8 Randhawa PS, Cetto R, Chilvers G, et al. Long-term quality-of-life outcomes in children undergoing adenotonsillectomy for obstructive sleep apnoea: a longitudinal study. Clin Otolaryngol 2011; 36: 475-481.

Martha VF, Moreira Jda S, Martha AS, et al. Reversal of pulmonary hypertension in children after adenoidectomy or adenotonsillectomy. Int J Pediatr Otorhinolaryngol 2013; 77: 237-240.

0 Tal A, Leiberman A, Margulis G, et al. Ventricular dysfunction in children with obstructive sleep apnea: radionuclide assessment. Pediatr Pulmonol 1988; 4: 139-143. 
Giordani B, Hodges EK, Guire KE, et al. Changes in neuropsychological and behavioral functioning in children with and without obstructive sleep apnea following Tonsillectomy. J Int Neuropsychol Soc 2012; 18: 212-222.

Lee TT, Lefebvre CE, Gans NE, et al. Quantifying respiratory complications post-adenotonsillectomy in patients with normal or inconclusive overnight oximetry. J Otolaryngol Head Neck Surg 2013; 42: 50.

Biavati MJ, Manning SC, Phillips DL. Predictive factors for respiratory complications after tonsillectomy and adenoidectomy in children. Arch Otolaryngol Head Neck Surg 1997; 123: 517-521.

Baugh RF, Archer SM, Mitchell RB, et al. Clinical practice guideline: tonsillectomy in children. Otolaryngol Head Neck Surg 2011; 144: Suppl., S1-S30.

Kheirandish L, Goldbart AD, Gozal D. Intranasal steroids and oral leukotriene modifier therapy in residual sleep-disordered breathing after tonsillectomy and adenoidectomy in children. Pediatrics 2006; 117: e61-e66.

Villa MP, Brasili L, Ferretti A, et al. Oropharyngeal exercises to reduce symptoms of OSA after AT. Sleep Breath 2015; 19: 281-289.

Guilleminault C, Huang YS, Monteyrol PJ, et al. Critical role of myofascial reeducation in pediatric sleep-disordered breathing. Sleep Med 2013; 14: 518-525.

Levrini L, Lorusso P, Caprioglio A, et al. Model of oronasal rehabilitation in children with obstructive sleep apnea syndrome undergoing rapid maxillary expansion: research review. Sleep Sci 2014; 7: 225-233. Kay DJ, Bryson PC, Casselbrant M. Rates and risk factors for subsequent tonsil

Wood JM, Cho M, Carney AS. Role of subtotal tonsillectomy ('tonsillotomy') in children with sleep disordered breathing. J Laryngol Otol 2014; 128: Suppl. 1, S3-S7.

Chaidas KS, Kaditis AG, Papadakis CE, et al. Tonsilloplasty versus tonsillectomy in children with sleep-disordered breathing: short- and long-term outcomes. Laryngoscope 2013; 123: 1294-1299.

Villa MP, Malagola C, Pagani J, et al. Rapid maxillary expansion in children with obstructive sleep apnea syndrome: 12-month follow-up. Sleep Med 2007; 8: 128-134.

Carvalho FR, Lentini-Oliveira D, Machado MA, et al. Oral appliances and functional orthopaedic appliances for obstructive sleep apnoea in children. Cochrane Database Syst Rev 2007; 2: CD005520.

Caldarelli V, Borel JC, Khirani S, et al. Polygraphic respiratory events during sleep with noninvasive ventilation in children: description, prevalence, and clinical consequences. Intensive Care Med 2013; 39: 739-746.

Ramirez A, Khirani S, Aloui S, et al. Continuous positive airway pressure and noninvasive ventilation adherence in children. Sleep Med 2013; 14: 1290-1294.

Marcus CL, Radcliffe J, Konstantinopoulou S, et al. Effects of positive airway pressure therapy on neurobehavioral outcomes in children with obstructive sleep apnea. Am J Respir Crit Care Med 2012; 185: 998-1003.

Uong EC, Epperson M, Bathon SA, et al. Adherence to nasal positive airway pressure therapy among school-aged children and adolescents with obstructive sleep apnea syndrome. Pediatrics 2007; 120: e1203-e1211.

Marcus CL, Rosen G, Ward SL, et al. Adherence to and effectiveness of positive airway pressure therapy in children with obstructive sleep apnea. Pediatrics 2006; 117: e442-e451.

Amaddeo A, Caldarelli V, Fernandez-Bolanos M, et al. Polygraphic respiratory events during sleep in children treated with home continuous positive airway pressure: description and clinical consequences. Sleep Med 2015; 16: $107-112$.

Beebe DW, Byars KC. Adolescents with obstructive sleep apnea adhere poorly to positive airway pressure (PAP), but PAP users show improved attention and school performance. PLoS One 2011; 6: e16924.

Korayem MM, Witmans M, MacLean J, et al. Craniofacial morphology in pediatric patients with persistent obstructive sleep apnea with or without positive airway pressure therapy: a cross-sectional cephalometric comparison with controls. Am J Orthod Dentofacial Orthop 2013; 144: 78-85.

Prashad PS, Marcus CL, Maggs J, et al. Investigating reasons for CPAP adherence in adolescents: a qualitative approach. J Clin Sleep Med 2013; 9: 1303-1313.

DiFeo N, Meltzer LJ, Beck SE, et al. Predictors of positive airway pressure therapy adherence in children: a prospective study. J Clin Sleep Med 2012; 8: 279-286.

Marcus CL, Beck SE, Traylor J, et al. Randomized, double-blind clinical trial of two different modes of positive airway pressure therapy on adherence and efficacy in children. J Clin Sleep Med 2012; 8: 37-42.

Nixon GM, Mihai R, Verginis N, et al. Patterns of continuous positive airway pressure adherence during the first 3 months of treatment in children. J Pediatr 2011; 159: 802-807.

Koontz KL, Slifer KJ, Cataldo MD, et al. Improving pediatric compliance with positive airway pressure therapy: the impact of behavioral intervention. Sleep 2003; 26: 1010-1015.

Tahiri Y, Viezel-Mathieu A, Aldekhayel S, et al. The effectiveness of mandibular distraction in improving airway obstruction in the pediatric population. Plast Reconstr Surg 2014; 133: 352e-359e.

Taylor BA, Brace M, Hong P. Upper airway outcomes following midface distraction osteogenesis: a systematic review. J Plast Reconstr Aesthet Surg 2014; 67: 891-899.

9 Hartzell LD, Guillory RM, Munson PD, et al. Tongue base suspension in children with cerebral palsy and obstructive sleep apnea. Int J Pediatr Otorhinolaryngol 2013; 77: 534-537.

0 Guilleminault C, Li KK. Maxillomandibular expansion for the treatment of sleep-disordered breathing: preliminary result. Laryngoscope 2004; 114: 893-896.

Cohen SR, Ross DA, Burstein FD, et al. Skeletal expansion combined with soft-tissue reduction in the treatment of obstructive sleep apnea in children: physiologic results. Otolaryngol Head Neck Surg 1998; 119: 476-485.

Burstein FD, Cohen SR, Scott PH, et al. Surgical therapy for severe refractory sleep apnea in infants and children: application of the airway zone concept. Plast Reconstr Surg 1995; 96: 34-41.

Kremer B, Botos-Kremer AI, Eckel HE, et al. Indications, complications, and surgical techniques for pediatric tracheostomies - an update. J Pediatr Surg 2002; 37: 1556-1562.

Cohen SR, Suzman K, Simms C, et al. Sleep apnea surgery versus tracheostomy in children: an exploratory study of the comparative effects on quality of life. Plast Reconstr Surg 1998; 102: 1855-1864.

Tagaya M, Nakata S, Yasuma F, et al. Children with severe or moderate obstructive sleep apnoea syndrome show a high incidence of persistence after adenotonsillectomy. Acta Otolaryngol 2012; 132: 1208-1214.

Cozza P, Ballanti F, Prete L. A modified monobloc for treatment of young children with obstructive sleep apnea. J Clin Orthod 2004; 38: 241-247. 
Pirelli P, Saponara M, Guilleminault C. Rapid maxillary expansion in children with obstructive sleep apnea syndrome. Sleep 2004; 27: 761-766.

Villa MP, Bernkopf E, Pagani J, et al. Randomized controlled study of an oral jaw-positioning appliance for the treatment of obstructive sleep apnea in children with malocclusion. Am J Respir Crit Care Med 2002; 165: 123-127.

Tan E, Nixon GM, Edwards EA. Sleep studies frequently lead to changes in respiratory support in children. J Paediatr Child Health 2007; 43: 560-563.

Kushida CA, Chediak A, Berry RB, et al. Clinical guidelines for the manual titration of positive airway pressure in patients with obstructive sleep apnea. J Clin Sleep Med 2008; 4: 157-171.

Berry RB, Chediak A, Brown LK, et al. Best clinical practices for the sleep center adjustment of noninvasive positive pressure ventilation (NPPV) in stable chronic alveolar hypoventilation syndromes. J Clin Sleep Med 2010; 6: 491-509.

Tunkel DE, McColley SA, Baroody FM, et al. Polysomnography in the evaluation of readiness for decannulation in children. Arch Otolaryngol Head Neck Surg 1996; 122: 721-724.

Fishman G, Zemel M, DeRowe A, et al. Fiber-optic sleep endoscopy in children with persistent obstructive sleep apnea: inter-observer correlation and comparison with awake endoscopy. Int J Pediatr Otorhinolaryngol 2013; 77: 752-755.

Durr ML, Meyer AK, Kezirian EJ, et al. Drug-induced sleep endoscopy in persistent pediatric sleep-disordered breathing after adenotonsillectomy. Arch Otolaryngol Head Neck Surg 2012; 138: 638-643.

Revell SM, Clark WD. Late-onset laryngomalacia: a cause of pediatric obstructive sleep apnea. Int J Pediatr Otorhinolaryngol 2011; 75: 231-238.

Nandalike K, Shifteh K, Sin S, et al. Adenotonsillectomy in obese children with obstructive sleep apnea syndrome: magnetic resonance imaging findings and considerations. Sleep 2013; 36: 841-847.

Donnelly LF, Shott SR, LaRose CR, et al. Causes of persistent obstructive sleep apnea despite previous tonsillectomy and adenoidectomy in children with down syndrome as depicted on static and dynamic cine MRI. Am J Roentgenol 2004; 183: 175-181.

Shott SR, Donnelly LF. Cine magnetic resonance imaging: evaluation of persistent airway obstruction after tonsil and adenoidectomy in children with Down syndrome. Laryngoscope 2004; 114: 1724-1729. 